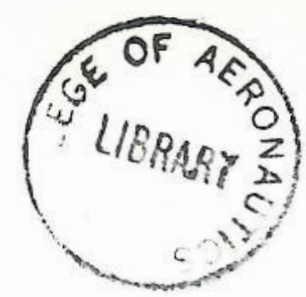

\title{
Research at the College of Aeronautics Cranfield
}

\author{
by \\ PROFESSOR A. J. MURPHY, M.Sc., F.R.Ae.S., F.I.M. \\ (The Principal, College of Aeronautics)
}

and THE STAFF OF THE COLLEGE

The 1,142nd lecture to be given before the Society and the 37th Main lecture to be held at a Branch Centre "Research at the College of Aeronautics" by Professor A. J. Murphy, M.Sc., F.R.Ae.S., F.I.M., Principal, College of Aeronautics, was given under the auspices of the Cambridge Branch on 21 st January 1960. Professor W. A. Mair, M.A., F.R.Ae.S. Francis Mond Professor of Aeronautical Engineering, University of Cambridge, and President of the Cambridge Branch, opened the proceedings and then handed over to the President of the Society, Mr. Peter G. Masefield, M.A., F.R.Ae.S. Hon.F.I.A.S., M.Inst.T.

Mr. Masefield: As an old Cambridge engineering man it was a great pleasure to be President of the Society in the year in which the first Main lecture was held at Cambridge.

One of the most important and significant developments in aeronautical education since the war had been the founding and the progress in recent years under Professor Murphy, of the College of Aeronautics at Cranfield. It had been founded just after 1944 as a result of the Fedden Committee of that year, set up by Sir Stafford Cripps, then Minister of Aircraft Production. Cranfield was primarily concerned with two things: post-graduate training in all branches of aeronautics and associated sponsored research by both staff and students of the College. Professor Murphy was to speak on the latter part.

British aeronautics today was passing through one of those periodic upheavals which seemed to happen every few years in this great business in which so many of them were engaged. Some of the changes now in progress he thought could mean a great difference in British aviation in the 50 years to come. compared with the 50 years that had gone by, and many of them he hoped would be concerned in these changes and in the new era of British aviation which was just beginning. He hoped that 1960 would mark the beginnings of a new chapter in aviation history as 1910 had done fifty years ago.

Over the past 50 years about 85 per cent of work in aeronautics in Great Britain had been in the military field; certainly 85 per cent of industrial effort. In future, manned military aircraft would be only a small proportion of the effort. The rest would be in missiles, civil aeronautics and space activities. In all of these they would be working increasingly competitively internationally and particularly with America and Russia. To make real impact their technology must be the highest possible. There was no doubt that the two foundation stones on which everything else had to rest were firstly, sound basic technical education and secondly. first-class research effort. At Cambridge, and 40 miles away at Cranfield, both those aims were being pursued. He could not over-emphasise the importance of these two subjects. The Society was closely concerned in both education and research and. therefore, it was an especial pleasure to introduce Professor Murphy.

Since October 1955 Professor Murphy had been Principal of the College of Aeronautics. Graduating from Manchester University in 1920 with First Class Honours in Chemistry, he had first done some research at University College, Swansea, before going to the National Physical Laboratory Metallurgy Department. In 1931, he had joined J. Stone and Company Ltd. as Chief Metallurgist and spent some years in Industry as a Director of that company and its associates. In 1950 he kecame Professor of Industrial Metallurgy at Birmingham University and, three years later, Director of the Departments of Physical and Industrial Metallurgy, a post he held until his appointment in 1955 as Principal of the College of Aeronautics. Professor Murphy had been President of the Institute of Metals and of the Institution of Metallurgists.

\footnotetext{
A LTHOUGH the circumstances of the foundation of the College of Aeronautics in 1945 may now be assumed to be fairly well known, it may be useful to recall what the Fedden Report of 1944 had to say about the place of research in the College of Aeronautics for which the Fedden Committee planned. The relevant parts of the Summary of Recommendations of the Report read as follows:-

" $i$. The primary purpose of the College should be to provide a high grade engineering, technical and scientific training in aeronautics to fit students for leadership in the aircraft industry, civil aviation, the Services, education and research.

iv. The instruction should be at postgraduate level or its equivalent, research should be under-
}

taken by staff and selected students, and attention should be paid to the technology as well as the science of aeronautics."

In the body of the Report several paragraphs are devoted to "The Place of Research," and these are worth quoting 15 years after they were written :

"The place of research in the College will influence its character and deserves some definition. The Aeronautical Research Committee regard as an important function of the College the introduction of selected students to research methods and participation in research and they thought it desirable that some of the staff should engage in research, primarily to maintain their own freshness and vigour. We endorse both of these recommendations. While the first duty of the staff must be to teach, 
participation in research is essential if they are to discharge this duty effectively."

This extract from the Fedden Report can be accepted today as a fair statement of the view we take on the place of research in our College.

The people directly engaged in research are the academic staff, Research Fellows, graduate research assistants and students in the second year of the Diploma Course. The establishment makes provision for three Senior and six Junior Fellowships and another Research Fellowship is endowed by the English Electric Co. Ltd. Research assistants are generally working, under the supervision of a senior member of staff, on researches supported through the medium of contracts by outside bodies, which may be Government departments or other concerns, within or outside the Aircraft Industry.

The physical resources available for research will be described in the course of the accounts which follow relating to the activities of the different departments. Because the departments do not have to undertake any appreciable amount of elementary laboratory demonstration, there is not the sharp distinction, which would otherwise be inevitable, between the equipment used in practical instruction and that intended primarily for research.

The intensity of the research effort varies among the departments. This is a consequence of several factors, such as the nature of the subject, the interests and inclinations of the Heads of Departments and their staffs, but probably the most weighty influence is connected with the history of the individual departments. During the time when an important new teaching development is being planned and brought into operation it is inescapable that the energies and time of the staff concerned tend to be diverted at least temporarily from research.

Just as the greatest freedom possible is given to the Head of each Department in the teaching for which he and his staff are responsible, so in research it is for him to decide the volume and general direction of the work undertaken in his department. Collaboration between departments in research is natural and common.

The main portion of this paper consists of contributions from the eight teaching departments and the Library. No attempt has been made to render them into a uniform style or mode of treatment: it is hoped that this method of presentation will convey a sense of that variation in approach and outlook on research which may be regarded as a sign of health in an academic institution.

The most common medium for publications of the results of researches at Cranfield is the series of "College of Aeronautics Reports." Up to the present time 123 of these have appeared. The normal distribution is 280 copies. "C. o. A. Reports" are well known in aeronautical engineering circles: they are regularly noted and reviewed in the Journal of the Royal Aeronautical Society, Applied Mechanics Reviews, Mathematics Reviews and the technical engineering journals. An increasing amount of matter arising from the research at Cranfield is of interest to those outside aeronautical circles: this applies particularly to work in the Departments of Economics and Production, Electrical Engineering and Materials. In these cases more effective dissemination and discussion of the results might be achieved by communicating them in the first instance to the appropriate learned societies, with

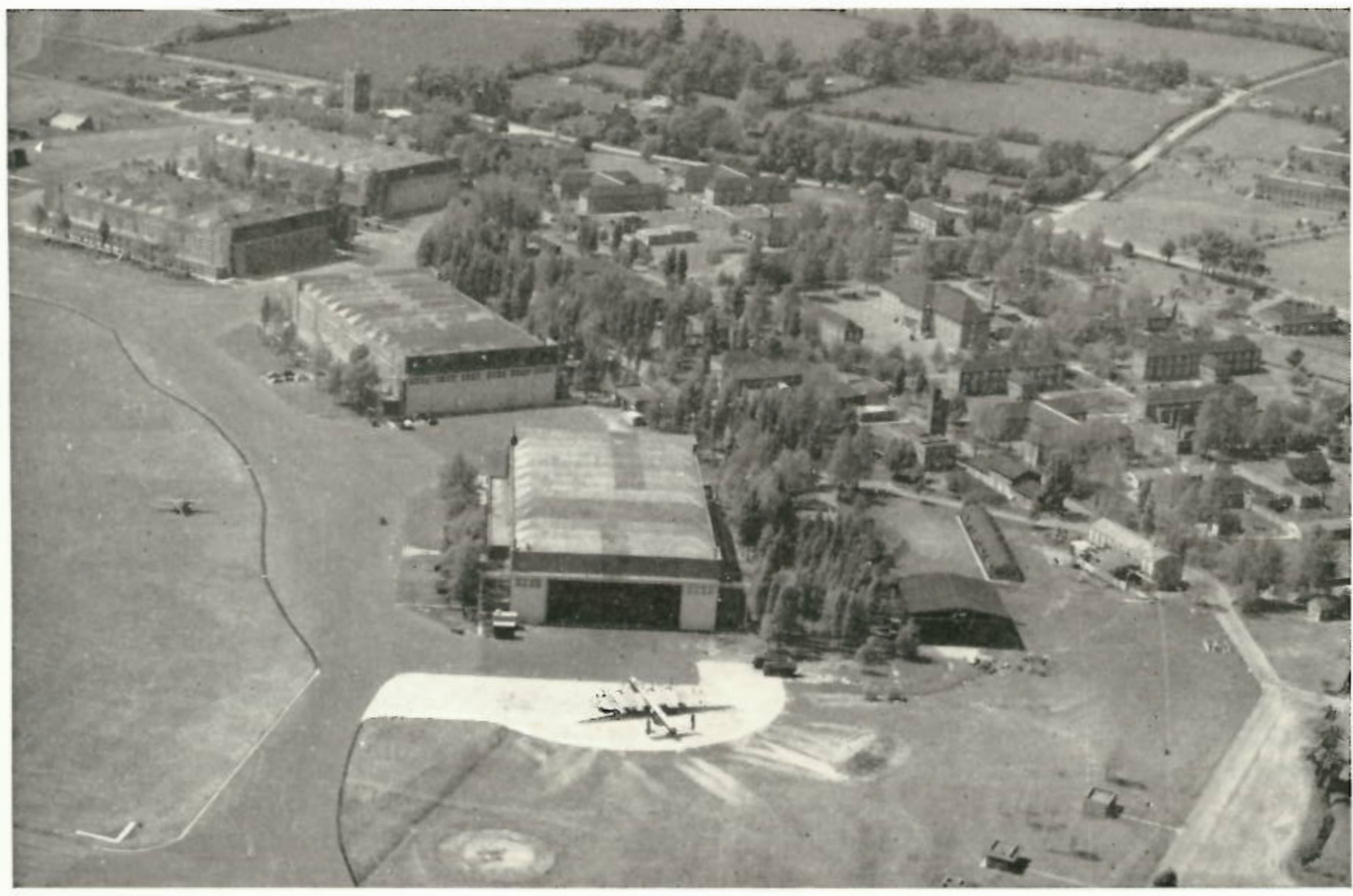

Figure 1. Aeria view of the College. 
eventual reproduction also in the College of Aeronautics Reports series. Attention would naturally have to be given to certain aspects of copyright.

The results of investigations of less importance are published as "College of Aeronautics Notes." The number of these published to date is 99. Students' Research Theses are submitted in uniform typescript and retained in the College Library, where they may be consulted by appointment.

\section{Department of Aerodynamics INTRODUCTION}

The research work of the Department of Aerodynamics over the past few years has covered a wide field of problems relating to hovering flight, vertical and horizontal landing and take-off, subsonic, transonic and supersonic flight and more recently to flight at hypersonic speeds.

On the experimental side the Department has facilities for testing over most of the speed range up to supersonic speeds and new hypersonic equipment is in the process of being installed. The 9 in. $\times 9$ in. supersonic tunnel is now fitted with a two-stage centrifugal compressor which enables the tunnel to operate up to a Mach number of 3. The tunnel is now complete with self-balancing potentiometers for force and moment measurement. The $8 \mathrm{ft} \times 6 \mathrm{ft}$. general purpose low speed tunnel has been in operation for nearly three years. This tunnel has a top speed of about $240 \mathrm{ft}$. $/ \mathrm{sec}$. (with screens). Its speed can be altered by varying the pitch of the fan blades manually, and an automatic blade pitch control will shortly be completed. The tunnel has a 6-component electro-mechanical balance manually operated, although it is planned to modify this to read-out automatically.

These two large tunnels are supplemented on the high speed side by a 6 in. $\times 4$ in. intermittent blow-down supersonic tunnel, a 2.5 in. $\times 2.5$ in. intermittent vacuum supersonic tunnel and a 2 in. $\times 2$ in. induction supersonic tunnel, and on the low speed side by an 18 in. $\times 12$ in. low turbulence wind tunnel with 6 screens and a contraction ratio of $50 / 1$, a $3.5 \mathrm{ft}$. diameter open jet tunnel, a $3.3 \mathrm{ft}$. elliptical twin open jet tunnel, a $3 \mathrm{ft} . \times$ $3 \mathrm{ft}$. straight-through tunnel and an 18 in. $\times 12$ in. straight-through tunnel, together with miscellaneous demonstration tunnels and smoke tunnels. The Department also has a $7 \mathrm{in} . \times 5 \mathrm{in}$. high speed tunnel operating with Freon 12 as the working medium in place of air. It is installing a high pressure shock tube of 2 in. diameter, and a 3 in. diameter helium tunnel for tests at hypersonic speeds. In addition the Department has a small hydraulics laboratory in which there is a hydraulic analogy channel for testing towed models simulating the transonic speed range, and a potential flow electrolytic tank for solving two-dimensional and axisymmetrical potential flow problems in fluid mechanics.

\section{JET NOISE (Refs. 1-5, T1)*}

The pioneering work on the noise from jets has

"References are listed at the end of the paper. The prefix " $T$ " indicates a reference to a Student's Thesis.

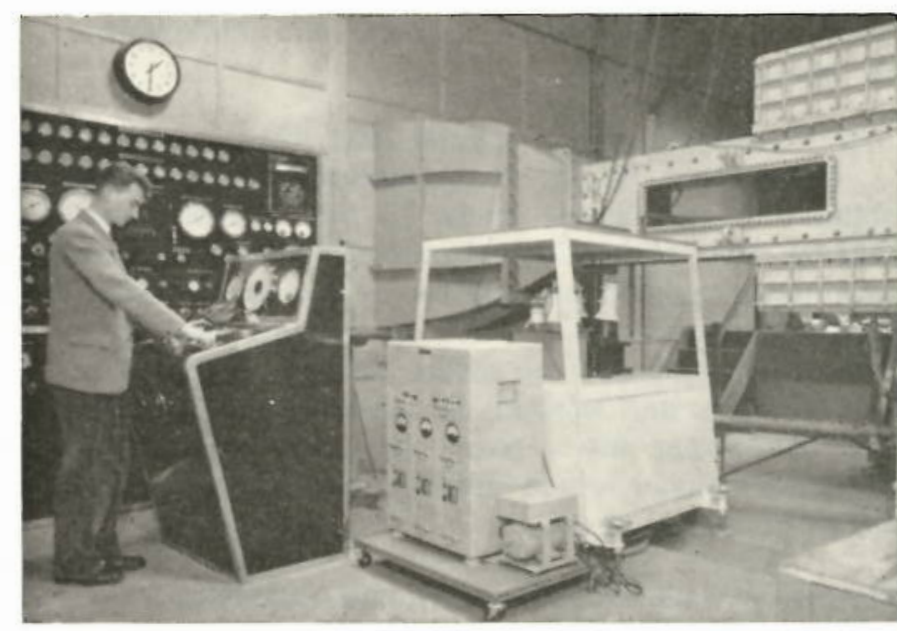

Figure 2. 9 in. supersonic wind tunnel.

continued in both the experimental and theoretical fields. The early experimental work which led to the toothed and corrugated nozzle as a flight noise reducing nozzle is being continued with promising results, as are developments of the wide angle diffuser type of ground muffler. The programme has been extended to include boundary layer noise, a field which is causing concern in the design of missiles and supersonic aircraft. This has led to the development of recording equipment using magnetic tape with a response up to $100 \mathrm{kc}$., and turbulence equipment for making space-time velocity and pressure correlations. These are required for the evaluation of the strength of the noise sources in jets and boundary layers, as well as for providing basic information on the structure of turbulent shear layers. The Lighthill theory of jet noise has been extended so that with the help of only a few assumptions the strength of the noise sources in a subsonic and low supersonic jet can be evaluated and thereby the directivity pattern of the noise in the radiation field can be obtained. The problem of noise from supersonic aircraft, including the "supersonic bang" problem, which today is seen as a problem of the first magnitude in connection with supersonic transport, has been investigated. Both the theoretical work and experiments in the hydraulic analogy channel made useful contributions in this field.

\section{INTERFERENCE AT SUPERSONIC SPEEDS}

(Refs. 6-11, T2-T3)

Experiments at a Mach number of 2 on the interference characteristics of low aspect ratio wings on cylindrical bodies, which materially helped in the understanding of the non-linear pitch-yaw coupling effects on guided missiles, were conducted in the 9 in. $\times 9$ in. supersonic tunnel (Fig. 2). This tunnel is now being used for research on jet-body interference and base drag at supersonic speeds and extends earlier work done in the $3 \mathrm{ft} . \times 3 \mathrm{ft}$. wind tunnel at subsonic speeds. In addition, lift and drag characteristics of missile head shapes have been measured experimentally in the 2.5 in. $\times 2.5$ in. supersonic tunnel at various supersonic speeds between Mach numbers of 1.8 and 3.3 and the results have been compared with slender body theory. This 
work is associated with the aerodynamic characteristics of shells and missiles.

USE OF FREON IN A WIND TUNNEL (Ref. 12)

Experiments on the characteristics of wings at high subsonic speeds in the Freon 12 wind tunnel showed that the effect of the different ratio of specific heats from that in air could be allowed for by the employment of the transonic similarity rules in reducing the results. This work confirmed the earlier work of von Doenhoff in the U.S.A. and showed the advantage, as to tunnel size and power for a given test Mach number and Reynolds number, which would be gained by the use of Freon 12 instead of air.

SLENDER WINGS AND BODIES AT LOW SUBSONIC SPEEDS (Refs. 13-22, T4-T7)

The characteristics of slender wings and bodies at low speeds have been the subject of much of the recent research work in the low speed tunnels. The loading and flow over a sharp-edged delta wing of $40^{\circ}$ apex angle have been obtained experimentally, and a theoretical model has been explored in the potential flow tank. The longitudinal and lateral oscillatory characteristics of sharp-edged fins and wings have also been obtained. The effects of cambering the head and tail of a circular fuselage, pointed at both ends, have been measured in order to determine the camber line shape associated with the maximum pitching moment for no drag increase.

JET WINGS AND JET LIFT (Refs. T8 and T9)

The use of spanwise jet blowing on slender wings as a means of control and of increasing the maximum lift has been demonstrated in tests on a swept wing and a body of revolution, and is the subject of work on a cropped delta wing. The aerodynamic characteristics of circular wings near the ground ("hovercraft" principle) have also been investigated with a view to the determination of the flow structure. In the field of vertical take-off the characteristics of a jet normal to a stream have been obtained.

POWERED-LIFT SYSTEMS (Refs. 23-25, T10)

Theoretical work is in progress on the problem of the jet flap with ground effect. The problem of flow separation has been demonstrated by experiments on a circular cylinder with a jet for which the inviscid theoretical solution was obtained from tests in the potential flow tank.

Preliminary theoretical work has been done on the application of the jet flap principle to helicopters, indicating advantages that warrant further development of such arrangements. A similar study has been made of convertiplane configurations in which the helicopter feature of long hoverability is combined with the aeroplane feature of high forward speed.

The inherent instability of a conventional helicopter when hovering has been studied mathematically and it has been shown how automatic stabilisation can be effected by a simple mechanical system without the assistance of electronic devices.
BLADE FLUTTER (Refs, 26-29, T11)

Previous work on the flexure-torsion flutter of aerofoils in cascade has been extended to the case of aerofoils with incidence over a wide range of stagger. This work, although not of direct interest to the design of compressor and turbine blades, at least draws attention to some of the major design problems.

\section{PROJECT ACTIVITIES (Ref. 30)}

Recent project studies on different types of aircraft include a canard layout, at a Mach number of 3, photographic reconnaissance aircraft, a Mach number 1.5 low level bomber and an "ogee" wing, Mach number 2, supersonic air liner. Low speed wind tunnel tests have been conducted to explore the longitudinal and lateral characteristics of these projects. The non-linear lift effects have proved most enlightening.

\section{MAN POWERED FLIGHT (Ref. 31)}

The challenge of the man powered aeroplane was taken up a few years ago and tests were made on the wing characteristics, longitudinal and lateral characteristics, as well as the power output from cyclists. The problem of power storage by stretched rubber has been investigated. The results of these various tests show without doubt that a man with suitable skill is capable of flying by his own effort.

\section{HELIUM HYPERSONIC WIND TUNNEL AND SHOCK TUBE (Ref. 32)}

The design and installation of a shock tube (Fig. 3) and a pilot hypersonic tunnel using helium as the working medium have been undertaken, as well as the

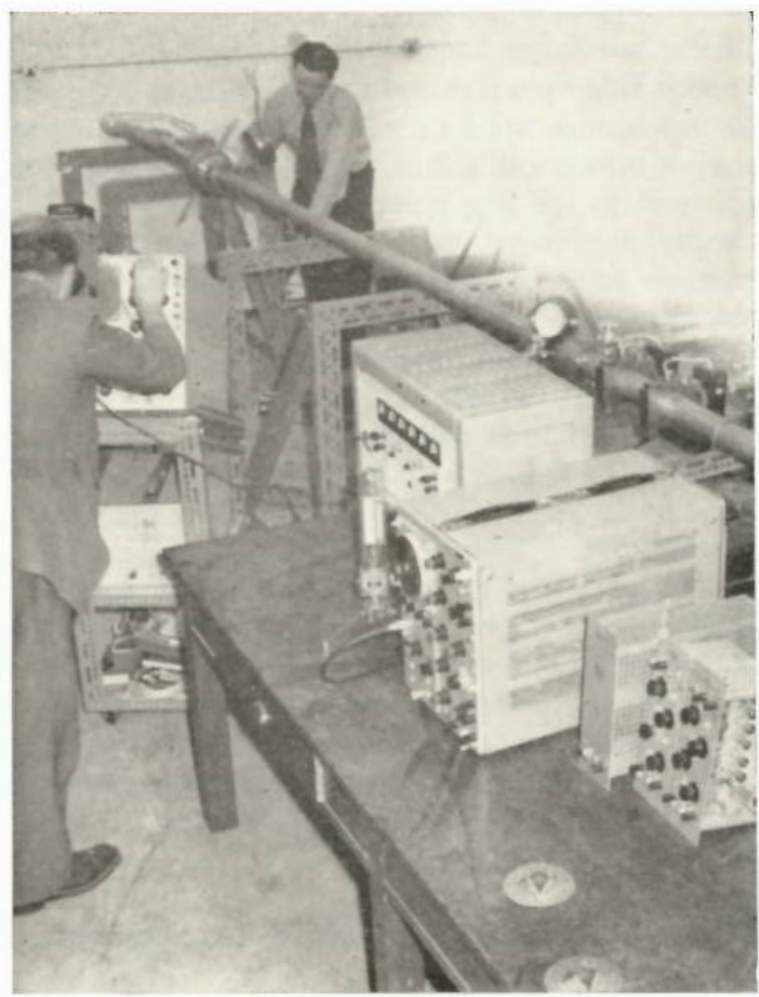

Figure 3. Shock tube. 
development of a new short-duration high light intensity spark source, a Schlieren interferometer using polarised light and a Mach-Zehnder interferometer. The design of axisymmetric nozzles for a helium tunnel with boundary layer corrections has been programmed on the Oxford "Mercury" digital computer.

Theoretical work in the field of real gas effects associated with the high temperatures present in hypersonic flows has been developed, covering problems of real gas effects in boundary layers, expansion round a corner, and sound absorption and dispersion. Experimental studies of these problems are being conducted in the shock tube.

HEAT TRANSFER IN DISSOCIATED GASES (Refs. 33-34)

This problem arises during hypersonic flight, where the gas temperatures achieved are sufficient to dissociate most of the atmospheric oxygen molecules, some of the nitrogen, and also to cause some degree of ionisation.

An early Couette flow study of a pre-dissociated diatomic gas (oxygen, for example) showed the significance of mass diffusion rates, since it is by these means that the chemical energy is transported through the gas, and also indicated the importance of the region in which such chemical energy is liberated. Thus the final heat transfer rate to the walls of a body immersed in a dissociated gas can depend quite critically on the efficiency of the wall as a catalyst for the atomic recombination reaction. Work on the problem of heat transfer to a flat plate in which all recombination occurs on the surface has been undertaken, and the results have been confirmed by papers published recently in the U.S.A. Experimental work on heat transfer in dissociated gases will begin shortly in the shock tube.

\section{ABLATION (Ref. T12)}

The ablation of surface material into the boundary layer is another of the phenomena which may be encountered in hypersonic flight. The reductions in heat transfer rate to the interior of a missile which can be achieved by, for instance, allowing the surface material to vaporise can be significant, the process acting as a kind of self-regulating gas injection system. It is not immediately obvious whether a surface material of high or low latent heat of vaporisation is better in these circumstances, since, with a low value more mass is injected into the boundary per unit time, while with a high latent heat more energy is absorbed in vaporising the material and less will penetrate to the inner regions of the body. A simple Couette flow study shows that as high a value as possible is best. The theoretical work on ablation and injection is continuing with further Couette flow studies of more complex gas mixtures and an examination of vaporisation from the surface of a flat plate. Some preliminary experimental work on the melting of bodies at high temperatures has been begun using models made from eutectic lead-tin alloy at a Mach number of 2 .

GAS FLOWS WITH CHEMICAL REACTIONS (Refs, 35-37)

The general study of inviscid gas flows in which reactions occur is of importance in a number of fields. Recent work has shown the relationships existing between the speeds of sound in gases for which chemical reactions are either very fast or very slow and the velocity occurring at the throat of a Laval nozzle running under choking conditions. It is a measure of the extra complications introduced by the chemistry that all of these speeds will in general be different.

The flow of a dissociated gas has been examined using a linear theory which has been shown to agree well with exact characteristics computations. This theory has pointed the way to a possible shock tube experiment to measure reaction rates in pure gases and further work is proceeding on more complicated gas mixtures.

The correct design of nozzles for shock tunnel facilities is a further important problem in this field. This is being examined using characteristics theory.

\section{MAGNETOGASDYNAMICS (Ref. T13)}

Theoretical work on the interaction between magnetic and electric fields and ionised, conducting gases has been started, and an extension of some previous Canadian work has been made which is relevant to possible experiments that can be conducted in an annular shock tube. This is concerned with the effects of continuum radiation from the hot gas and perturbations induced in the applied magnetic field on the conditions necessary for observable interactions to appear.

Present work includes a theoretical and experimental investigation of the Kolb or T-tube, in which shock Mach numbers of 400 and exceptionally high plasma temperatures can be achieved.

\section{HEAT CONDUCTION (Ref. 38)}

The advent of short-duration test facilities has focused attention on transient phenomena in gases, an example being the sudden contact between a hot gas and a cold wall. In these circumstances it is strictly necessary to include the effects of gas compressibility in treating one-dimensional unsteady heat conduction problems in gases. A theoretical treatment valid for un-ionised monatomic gases has indicated the nature of the pressure and temperature perturbations resulting from sudden contact between a semi-infinite cold solid and a semi-infinite hot gas. Further work includes the effects of chemical reactions and molecular structure and shock tube experiments designed to check the theory.

\section{FUTURE RESEARCH IN HYPERSONIC AERODYNAMICS}

The new shock tube is designed to operate at maximum driver pressures of 1,000 atmospheres. It will be fitted with a convergent-divergent nozzle and 12 in. diameter working section to produce Mach numbers of about 15 with maximum stagnation temperatures of $8,000^{\circ} \mathrm{K}$. Several research programmes are planned and will be concerned initially with the physical properties of dissociated gases with reference to their aerodynamic effects. 
At present, the variation of temperature with time at the interface of a hot gas placed suddenly in contact with a cold wall is being investigated. The surface temperature is measured by means of a thin-film resistance thermometer at the closed end of the low pressure section of the shock tube. A shock wave is reflected from this end and consequently hot gas is placed in contact with the wall. This experimental work is being done to check theoretical predictions.

The helium hypersonic tunnel mentioned earlier will operate in the Mach number range 5 to 25 with a stagnation temperature of about $300^{\circ} \mathrm{K}$, and will have a running time of $30 \mathrm{sec}$. The research programme so far planned will include the study of shock wave boundary layer interaction at hypersonic speeds.

In addition to hypersonic research, experimental apparatus for studying magnetogasdynamic effects is being built up. At present a magnetogasdynamic shock tube, known more generally as a Kolb tube, is being run to gain some insight into the fundamentals of magnetogasdynamics. A spark discharge is produced in a gas at low pressure and the interaction of the plasma with a suitable magnetic field causes a shock wave to propagate along a glass tube. Mach numbers of 50 in air have so far been achieved and at present the capacitive storage is being increased to 2,000 joules so that stronger shocks can be generated.

\section{Department of Aircraft Design INTRODUCTION}

Research in the Department of Aircraft Design is carried on by members of the teaching and research staff, as well as by students, under the direction of the staff, working on their research or project theses. The wide range of subjects covered includes design studies of aeroplanes as well as special investigations into engineering and scientific problems of practical interest. Emphasis is placed upon the unity of theory, experiment and design practice.
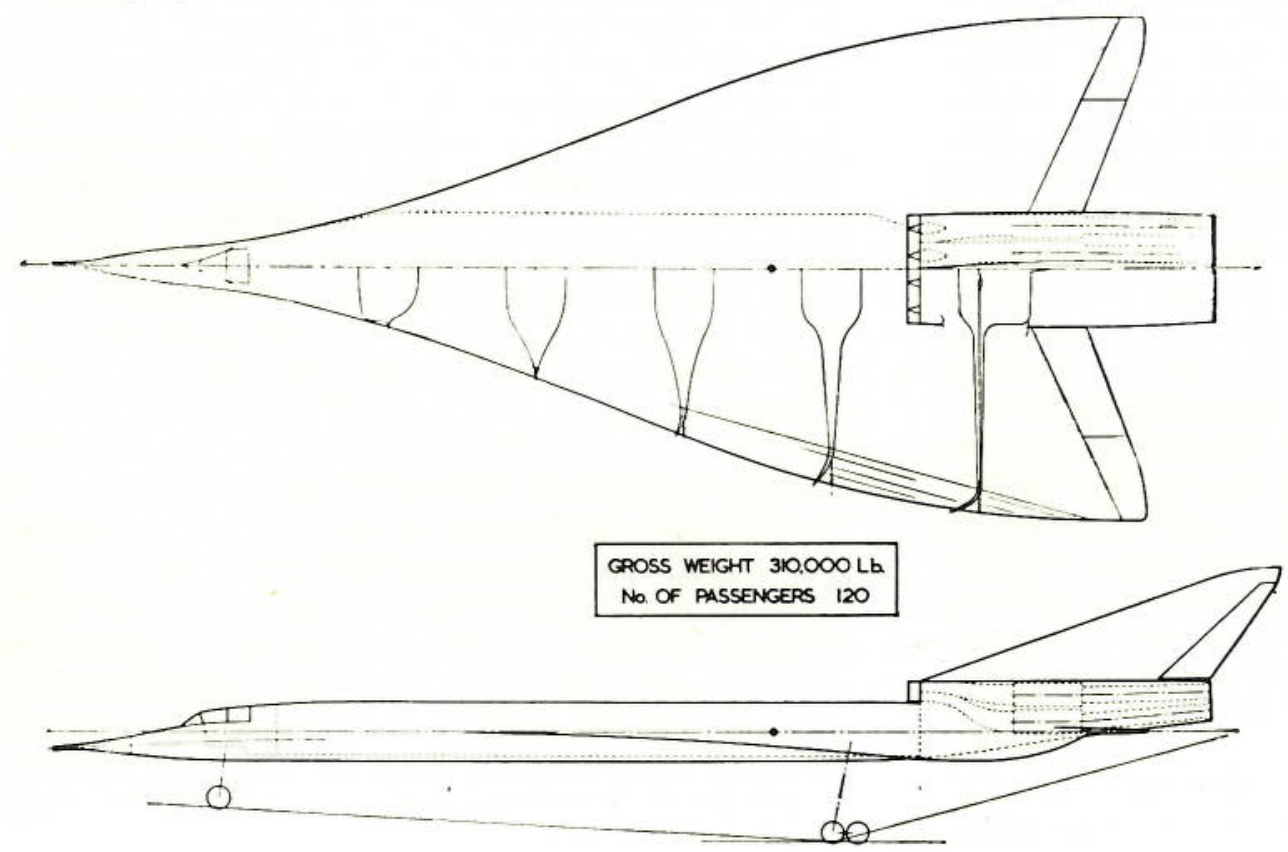

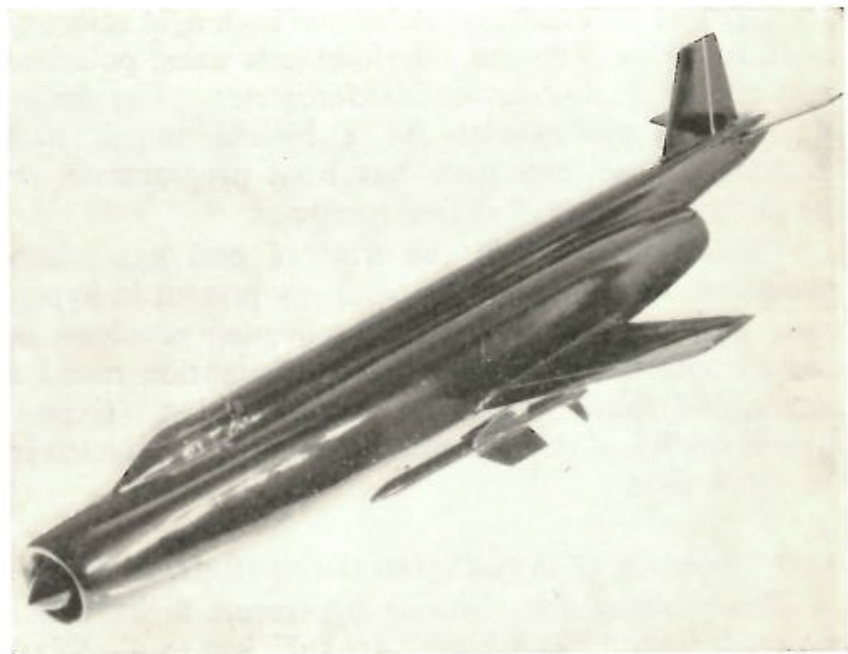

Figure 4. Mach 2 tighter (1953 project).

The purpose of much of the research is instructional. The aim is to teach students the art of research by giving them the opportunity, under the general direction of a member of staff, of investigating an individual problem for themselves. As might be expected, this exercise does not always produce, in the time available, complete and satisfactory answers to the problems posed. However, attempts by succeeding generations of students, combined with individual work by staff members often yield results of value.

\section{DESIGN STUDIES OF AEROPLANES}

The object of research in this field is to gain knowledge of what form the best design of aeroplane should take so that the resulting flying machine may meet a certain specification or perform a certain rôle. The solution to any problem of this kind should specify the aerodynamic configuration, the power plant, the materials and type of construction and the nature of the auxiliary systems. It must be completely practical both in relation to manufacture and operation and as far as possible must be demonstrated to be an optimum in relation to all-up weight, initial and running cost and operational efficiency.

A preliminary study of one, or sometimes two, aircraft or guided missiles is carried out each year by staff in the department. There is close co-operation with the Aerodynamics Department, and much advice on special problems is obtained from other departments of the College. A general arrangement drawing and a weight

FIGURE 5. Supersonic air liner (1960 project). 
estimate are produced, and the design work is then handed over to a team of second year Diploma students, each of whom carries out the detail design of a component, and submits his results as a thesis in part fulfilment of the requirements for the Diploma of the College. The students are expected to design their components to standards of adequate strength and stiffness, to minimise the weight and to ensure the practicability of constructional methods and functions. They must realise in hardware the general concept of the design.

One of the more recent projects is shown in Fig. 4. A glimpse into the future is provided in Fig. 5, which shows a supersonic transport under consideration now for this year's design study. These designs sometimes show an interesting resemblance to the solutions derived by the aircraft firms. This coincidence of thinking is interpreted as an indication that the project work in the Department of Aircraft Design is proceeding along sound lines. The problems involved in the incorporation of the tail-first configuration, the installation of engines in the rear of the fuselage, variable intakes, steel sandwich construction and integral skins of high tensile steel, were tackled as serious design projects in the department before their application by the Industry was generally known.

The purpose of project design studies in a teaching establishment is two-fold. In the first place they provide up-to-date material for students' instruction of a kind which could not be obtained from published information, but which is certainly necessary to give adequate training to those about to enter the Aircraft Industry in responsible positions. In the second place they serve to keep the staff of the department closely in touch with the latest problems of aeronautical practice. Reading the literature and talking to engineers in the Industry is valuable, but actually doing the job oneself is the most rewarding of all.

\section{LABORATORY FACILITIES}

The majority of the special research investigations carried out in the department fall under the headings of Applied Mechanics or, in particular, Structures. Experimental work in these fields requires equipment which will supply a realistic environment for the test specimens, as well as measuring equipment to record the effects produced.

The first requirement is to impose forces and constraints. The laboratories are equipped with some eight standard testing machines with load ranges up to 70 tons in tension and 150 tons in compression and include a 35 ton Losenhausen Fatigue machine. There are also a number of loading frames, the most recent of which is a "cruciform rig" (see Fig. 6) with four testing bays mounted on a central block of reinforced concrete in the form of a $10 \mathrm{ft}$. cube. Six electromagnetic excitors are available for vibration testing, and elastic mountings for dynamic models of aeroplanes are a standard facility. The special problems of drop testing of undercarriages are catered for by a swinging link machine, mounted above a moving $12 \mathrm{ft}$. diameter flywheel, which

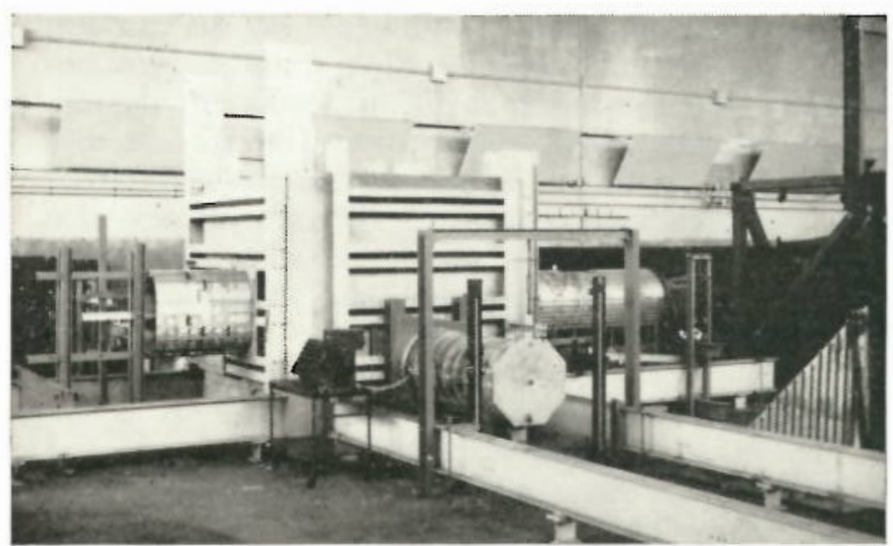

FIGURE 6. Crucitorm test rig.

enables the correct relative velocity between wheel and ground to be achieved, and so permits drag and side loads on the wheel to be realistically represented. This unique installation is shown in Fig. 7.

The special problems associated with the simulation of kinetic heating effects in aeroplane structures have led to the installation of many small heating units and controllers, which have been used in student thesis work. A larger facility with a capacity of one megawatt is in the course of construction.

The laboratories are well equipped with measuring

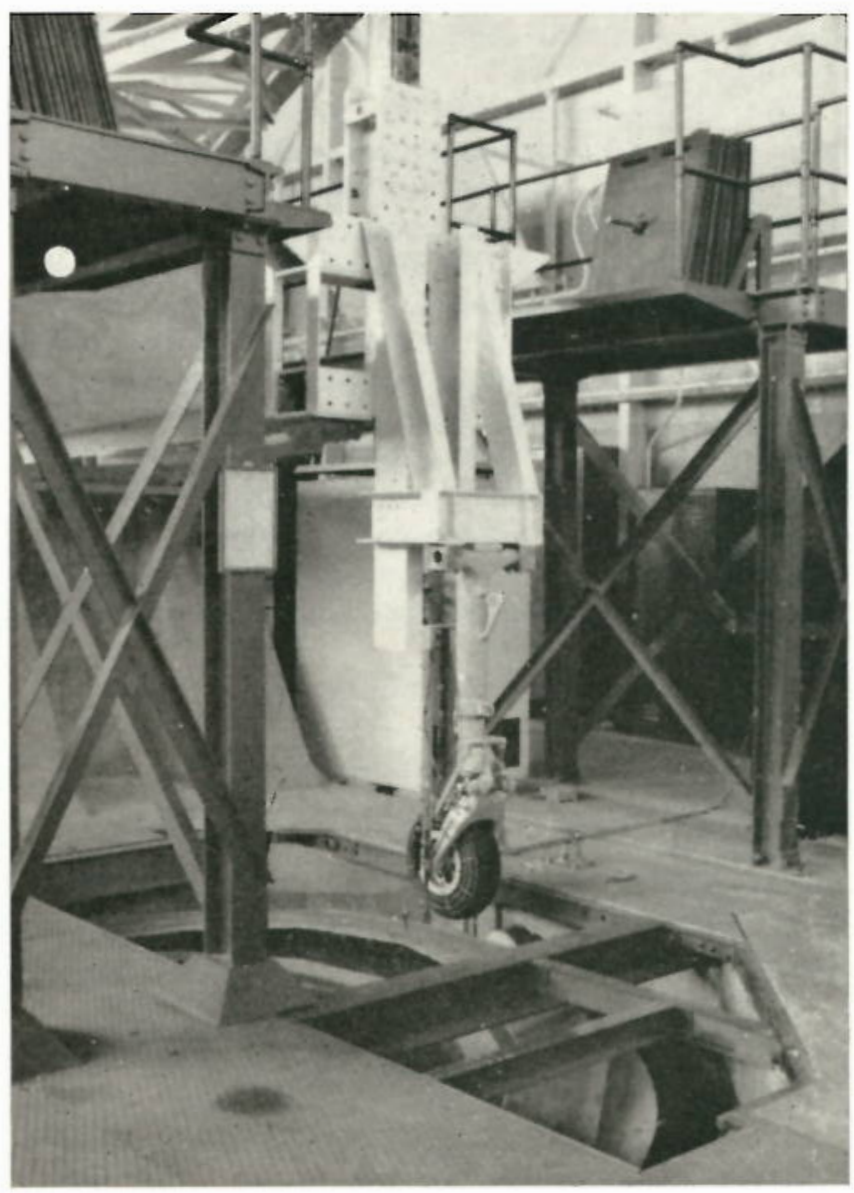

Figure 7. Drop test rig. 
and recording apparatus. Strain gauge bridges can deal with some 450 static readings, while recording galvanometers can deal with up to 100 transducer or thermocouple signals. Photo-elastic measurements are also made, both in the orthodox manner and also by a reflection technique, which uses the transparency as a strain indicator attached to the surface of a metal specimen under test. Pioneer work carried out in this last field is described in Ref. 39.

\section{STRUCTURES RESEARCH}

The basic problems of the theory of structures are concerned with stress distribution, deformation, buckling, plastic flow including creep, and fracture under both static and fatigue conditions. The development of mathematical theories for the prediction of these phenomena and their verification by experiment characterise most of the departmental research and the students' thesis investigations. Problems of optimum design for both general and special structural forms are also receiving attention. The use of electronic digital computers is a growing feature of many of the investigations.

The problems presented by delta and other low aspect ratio wings have been the subject of many studies. The use of oblique Cartesian co-ordinates introduced in Ref. 40 and applied to multi-web structures in Ref. 41 has been the basis for the theoretical side of much of this work, (see, for example, Refs. 42 and 43). Specimens tested have included solid plates as well as built up structures $^{\text {(T14-T17). }}$.

The stress distribution in pressure cabins with particular reference to reinforcing member stiffness and to cut-outs has been a special feature ${ }^{(44,45)}$. The theoretical analysis of stress concentration at plain and reinforced cut-outs of various shapes, including the square with rounded corners, by the complex variable methods of Muskhelishvili has been successfully carried out. Both conformal transformation and the direct use of integral equations has been considered ${ }^{(\text {T18-T20)}}$. The problems which arise when spherical and cylindrical shells are joined together have been studied ${ }^{(46)}$. This has an application to nuclear reactor design.

Much attention has been given to problems associated with thermal effects. Experimental checks

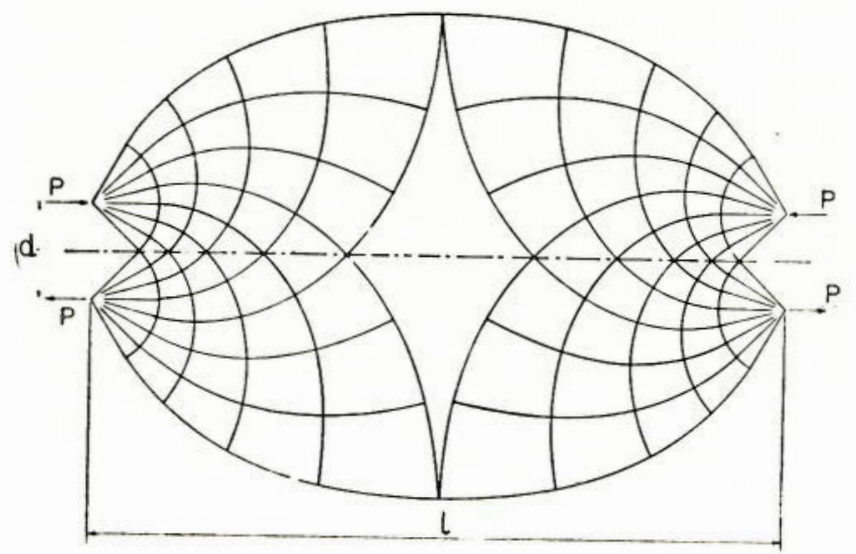

FIGURE 8. Optimum structure for pure bending moment. have been made on the temperature distribution in multi-web boxes and the thermal resistance of joints has been studied $\left.{ }^{\{21}, \mathrm{T}_{22}\right\rangle$. The thermal stress distributions in finite length multi-web boxes and in stiffened cylindrical shells have been investigated ${ }^{(47,48)}$, and measurements have been made of the loss of stiffness of plates heated at their edges. A study of incremental collapse, as predicted by E. W. Parkes, is in hand, but experimental difficulties associated with the production of rapid cooling have been experienced. Basic theoretical work has also been carried out in the field of thermo-elasticity ${ }^{(49)}$.

Investigations into the buckling of stressed skin and sandwich construction have been common over the years among the research thesis subjects ${ }^{\left(\mathrm{T} 23, \mathrm{~T}^{24}\right)}$. Recent studies have been concerned with the effects of plasticity on the buckling of plates in shear ${ }^{(50,}{ }^{255}$. These have confirmed the fact that the physically correct "flow theory" over-estimates buckling stresses, while the "incremental theory" is in better agreement with experiment. Some theoretical work has also been carried out in the field of creep buckling and experimental work is in hand $\mathrm{d}^{(\mathrm{T} 26)}$.

Studies are being made of the stress distribution in problems of contained plasticity. It is expected that difficulties of numerical analysis will be overcome by the use of an electronic digital computer. The accuracy of creep laws under conditions of varying stress is being investigated. The results should have an important bearing on the problems of creep buckling.

Extensive experimental investigations have been made into the fatigue strength of detail parts and into the propagation of cracks in sheet under steady and fatigue conditions. Theoretical work on cumulative damage has had some measure of success, but attempts to find regularities in crack propagation rates under varying fatigue stress levels have been abortive (T27-T29).

Experimental investigations have been made into the performance of bearings under high pressure and at elevated temperatures with a view to assessing their functioning for control surfaces in fighter wings ${ }^{(51)}$.

Theoretical investigations have been carried out in the manner of Michell into the optimum layout of framed and plate structures. Mathematical developments have been reported in Ref. 52 and applications, using the analogy with the slip line field in twodimensional plastic flow, have been made to the design of cantilevers under tip load and to beams carrying a pure bending moment. The lightest and stiffest known structure for the transmission of a pure bending moment is shown in Fig. 8. Optimum studies have also been made of particular constructional forms. Multi-web boxes are considered in Refs. 53 and 54, and pressurised cylinders in Ref. 55.

\section{VIBRATION RESEARCH}

Vibration analysis plays a vital part in aircraft design. Aeroplanes are often so flexible that vibrations induced by suddenly applied loads, for example gusts or landing reactions, play a significant part in their stress analysis. Aeroelastic instability or flutter is often the 


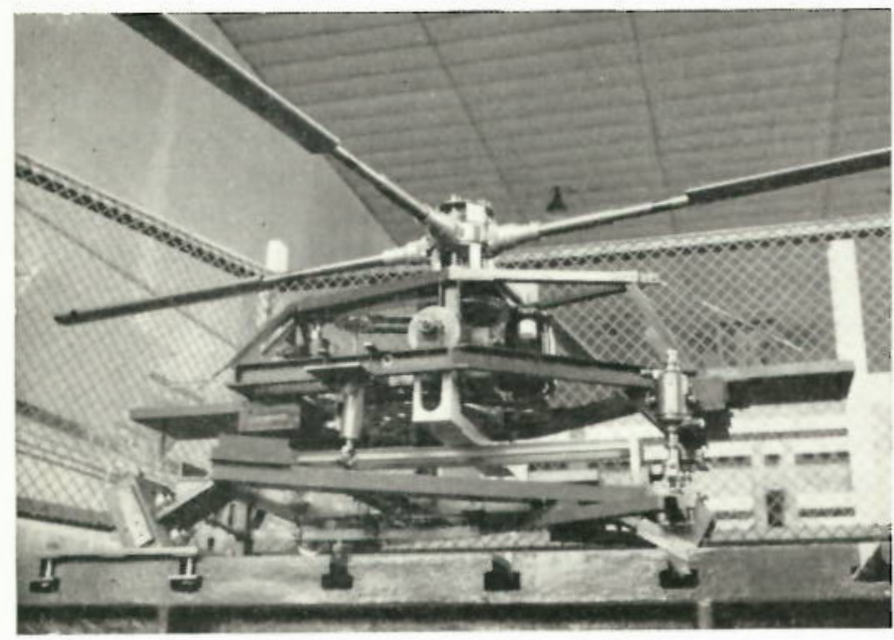

Figure 9. Helicopter test rig.

main "design case" for the structural design of a wing or similar surface. The flexibility of the "narrow delta" configuration has a decisive influence on its longitudinal stability. A knowledge of the modes of vibration is thus a necessary preliminary to satisfactory design.

The design of vibration models of aeroplanes, as a means for the prediction of normal modes in the early stages of design, has always been a feature of the Department's work ${ }^{(T 30)}$. Recent studies have made use of such models, equipped with undercarriages, to study the loads experienced by outriggers during landing and design information thus obtained was used on one of the aircraft projects ${ }^{(\mathrm{T} 31)}$.

Studies have also been made of full scale resonance test analysis. The use of multi-point excitation has been investigated and the use of the vector response plotting technique, applied to critical cases with near coincident frequencies, has been examined ${ }^{(\mathrm{T} 32)}$.

Investigations have been made into methods for producing very light-weight models for flutter testing with a view to studying tail flutter. Panel flutter and divergence have been studied theoretically ${ }^{(56-58)}$ and work is now in hand to test the theory by wind tunnel experiments.

The subject of helicopter "ground resonance,"

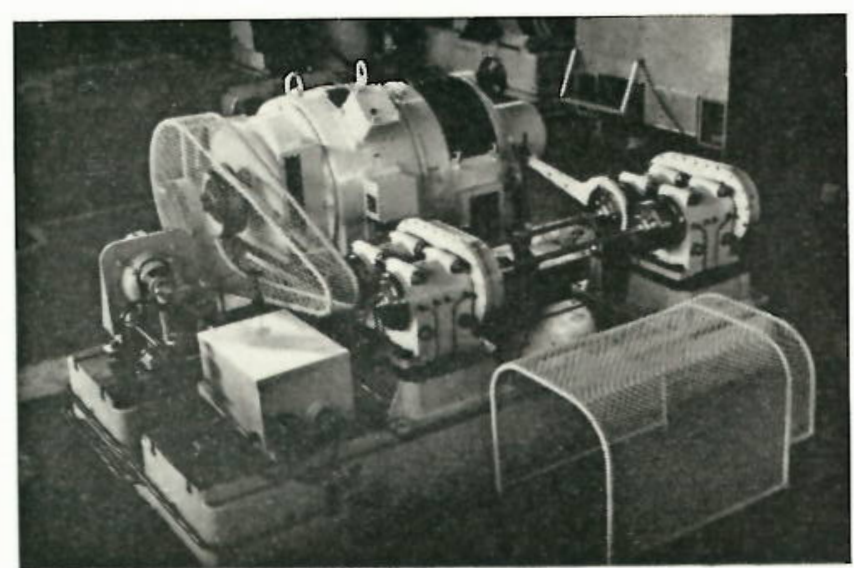

Figure 10. Gear test rig. which is a self-excited vibration involving coupling between movement of the blades about their drag hinges and the motions of the rigid aeroplane upon its undercarriage system, has been investigated theoretically and experimentally ${ }^{(\mathrm{T} 33-\mathrm{T} 36)}$. Considerable success has been achieved in predicting full scale phenomena by means of mechanical models. Some of the work is described in Ref. 59, and a picture of one of the models is shown in Fig. 9. The drag hinge dampers, which play a critical part in this phenomena, can be seen as well as the springs and dampers representing the suspension system of the aeroplane. Torsional vibration of helicopter transmission systems has also been studied ${ }^{(\mathrm{T3} 3)}$.

\section{Department of Aircraft Propulsion}

The research interests of this Department cover a wide field, since propulsion is achieved by a large variety of devices ranging from piston engines through gas turbines and ram-jets to rockets of various types. The rocket field will expand beyond conventional chemical rockets to thermal rockets, using hot hydrogen as the ejected fluid, and electrical rockets in which the ejected fluid is either a plasma or a jet of ionised particles (the so-called "ion rocket"). All the various propulsion devices throw up mechanical, chemical and fluid dynamical problems, and research in the Department has, therefore, been distributed over a wide range of fundamental subjects.

The equipment of the Department corresponds to the mechanical, thermodynamic, chemical and fluid dynamical fields mentioned, besides, of course, the normal teaching equipment of which actual engine test equipment forms a large and important part. Mechanical research is, for the most part, concentrated in two laboratories, the Mechanisms Laboratory and the Vibration Laboratory. Fluid dynamic research is spread over various laboratories, including the Hydraulics Laboratory, and chemical research is concentrated in the Fuels Laboratory. Equipment is further sub-divided into "quiet" and "noisy," the latter being located about half a mile from the centre of the College. In this "test area" is located the main departmental air supply, comprising four blowers, each driven by 500 h.p. motors. The air from these blowers is fed to a number of different test houses which were converted from the Royal Air Force bomb storage houses and have proved to be extremely useful laboratories. Twelve exist, each $26 \mathrm{ft}$. square and $14 \mathrm{ft}$. high.

\section{MECHANICAL RESEARCH}

Research in the mechanical field, over the past year or two, has concentrated on three main items.

The first of these, research into the dynamic loading of gear teeth, has been carried out under contract. Spur gears of about 9 in. diameter are run in a power circulating rig (Fig. 10) at speeds up to about 10,000 r.p.m. Extreme care is taken to align the test gears accurately. A particular tooth on one of the test gears is strain-gauged (Fig. 11), a piezo electric-type gauge of high sensitivity being used, and the signal taken out 


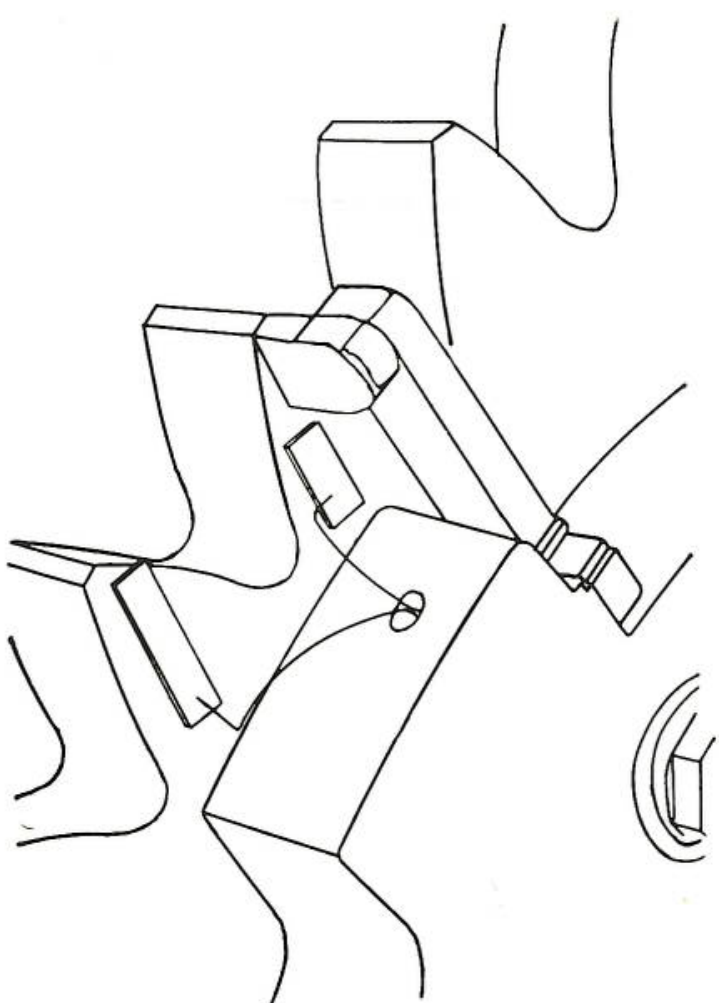

Figure 11. Test gear with piezo-electric strain gauge attached to side of tooth.

through slip rings. Recording of the signal from equipment of this type presents a variety of difficulties, particularly in respect of achieving economy of photographic material. Rather than use continuous film recording, a trigger device is adopted which permits recording to be restricted to the period during which the test tooth is in mesh. Maximum power transmission through the test gear is about 1,000 h.p., while the input power is lower by a factor of about 20 . The gear teeth pass through quite sharply defined resonances. The maximum stress so far indicated on the gear wheels tested has been about $1 \frac{1}{2}$ times the "static stress," i.e. about $1 \frac{1}{2}$ times the stress obtained when the gears are

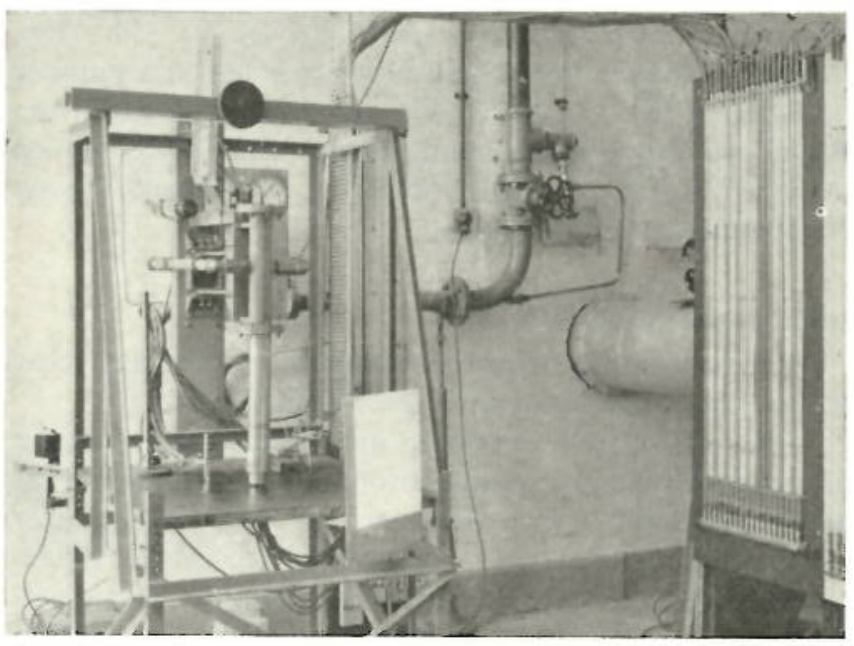

FIGURE 12. Rig for measuring ground proximity effects on nozzle thrust. rotating slowly enough for dynamic loading effects to be absent.

Bearing research has been carried out on a bearing rig, and has sought information on the relation between bearing temperature (anti-friction bearings) and oil flow quantities at various bearing loads and speeds, roller bearings of $2 \frac{1}{2}$ in. diameter bore used with speeds up to 10,000 r.p.m., and journal loads up to $100 \mathrm{lb}$. The rig simulates aircraft turbine conditions where low journal loads combined with high temperatures are met. To simulate the latter condition, the shaft is hollow and electrically heated. Thermocouples are attached to both the rotating and the stationary tracks of the bearings.

The third main item of mechanical research of the Department has been the investigation of the whirling of complex rotors. The theoretical approach to this subject is much more feasible nowadays than previously, since the extraction of the latent roots of the matrices which result from the theoretical investigation can now be done in a routine manner on digital computers. The rotor is a steel shaft $21 \mathrm{in}$. long and $\frac{1}{2}$ in. in diameter, and runs at speeds up to 5,000 r.p.m. It has mounted on it 6 steel discs, each 6 in. diameter, and the dynamic equation of motion, taking into account gyroscopic forces, results in a $24 \times 24$ matrix. The rotor is driven by a small air turbine which is, in fact, one of the discs, and is supported on two bearings. The new feature of this rig is that the flexibility of the bearing supports is

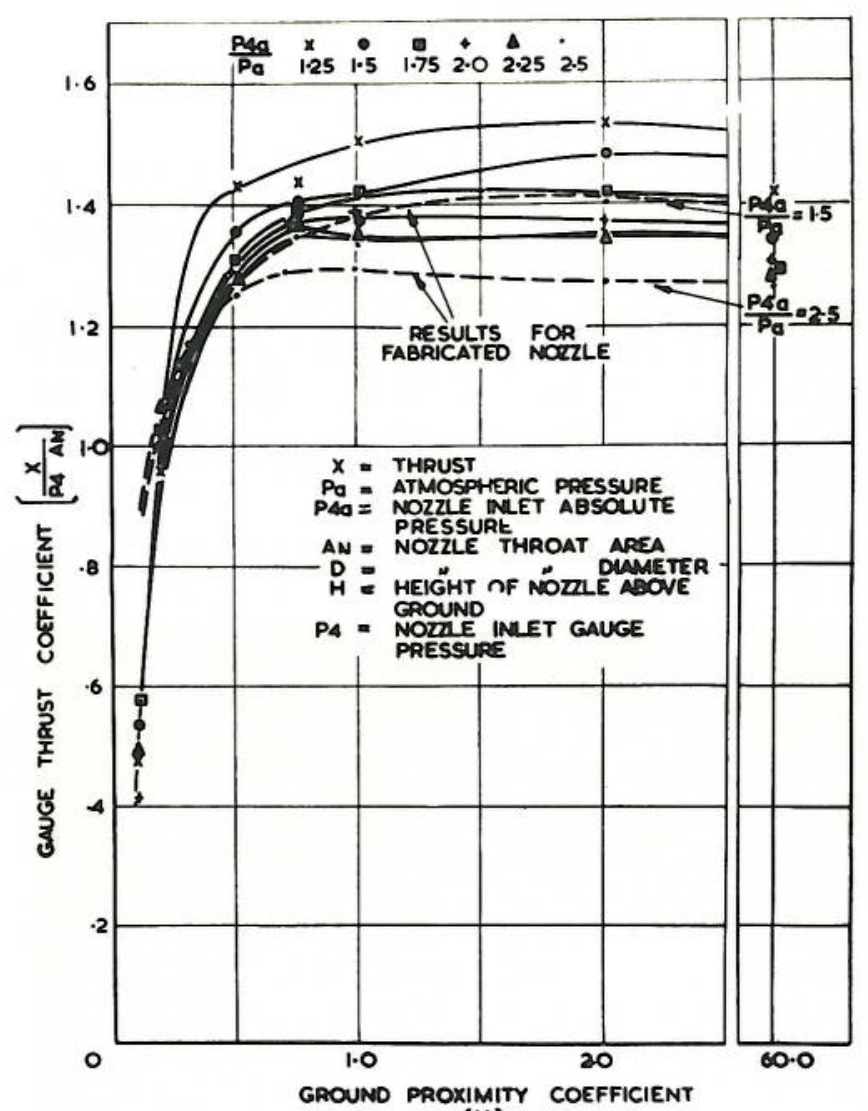

$\left(\frac{H}{0}\right)$

FIGURE 13. Variation of gauge thrust coefficient with ground proximity coefficient for $30^{\circ}$ machined convergent nozzle. 
FIGURE 14. Variation of mass flow coefficient with ground proximity coefficient for $30^{\circ}$ machined convergent nozzle.

allowed for in the theory; each of the bearings is actually supported by four strong helical springs. By this means it is possible to have anisotropic stiffness in the bearing supports. For instance, the bearing supports can be made more flexible in, say, the horizontal direction than in the vertical direction. This variation of stiffness with direction makes it possible for the phenomenon of "reverse whirl" to occur in the rotor. This effect has actually been observed, deflection of the rotor being detected by electrical pick-ups working on the change of capacity between the rotor and a neighbouring electrode as the rotor is deflected. Display of the signal from such pick-ups permits the detection of the magnitude and direction of a whirling vibration. Further, the various forward and reverse whirls have been watched with a specially developed stroboscope which shows the shaft rotating at 1/64 of its actual speed. It is intended to continue this work up to the whirling of a complete system simulating a complex rotor and a casing. It might be mentioned in passing that there appear still to be some mathematical difficulties in treating a problem of "reverse whirl." However, the critical speeds calculated for this rotor agree quite well with the experimental ones ${ }^{(\mathrm{T} 38)}$.

\section{AERODYNAMIC RESEARCH}

Aerodynamic research is usually carried out in the "test area" where there need be no noise limitations. For the most part air supplies for aerodynamic research come from the blower totalling 2,000 h.p., but small high-power demands are met by a 180 h.p. supply at 8 atmospheres, or by air bottles charged up to 2,000 p.s.i.

An example of the aerodynamic research of the Department is the work on the effect of ground proximity on the thrust produced from an engine producing a downward jet. This subject is of some current interest in view of the advent of vertical take-off and landing aircraft using lifting jets. Small nozzles were arranged to be fed with air up to 8 atmospheres in

Figure 15. Aerodynamic smear patterns near the exit from a nozzle. pressure and were held in a force balance. A photograph of the rig is shown in Fig. 12 and typical results are given in Figs. 13 and 14 . It will be noted that for the " $30^{\circ}$ machined convergent nozzle," when the ground is within half of a nozzle diameter of the end of the nozzle, the thrust begins to fall off appreciably. This is due to suction on the flat end of the nozzle. Results were not carried right down to zero distance from the ground; had they been, the thrust as presented nondimensionally would have been unity. The difference in results as between the "fabricated nozzle" and the " $30^{\circ}$ machined convergent nozzle" is due mainly to the fact that the former had a sharp end, whereas the latter had a "flat end" whose outside diameter was 1 in. as compared with the nozzle diameter of $\frac{1}{2}$ in. Thus suction effects were greater on the "machined nozzle." The air flow in the region of the nozzle exit was investigated both by the normal Pitot and static measure-

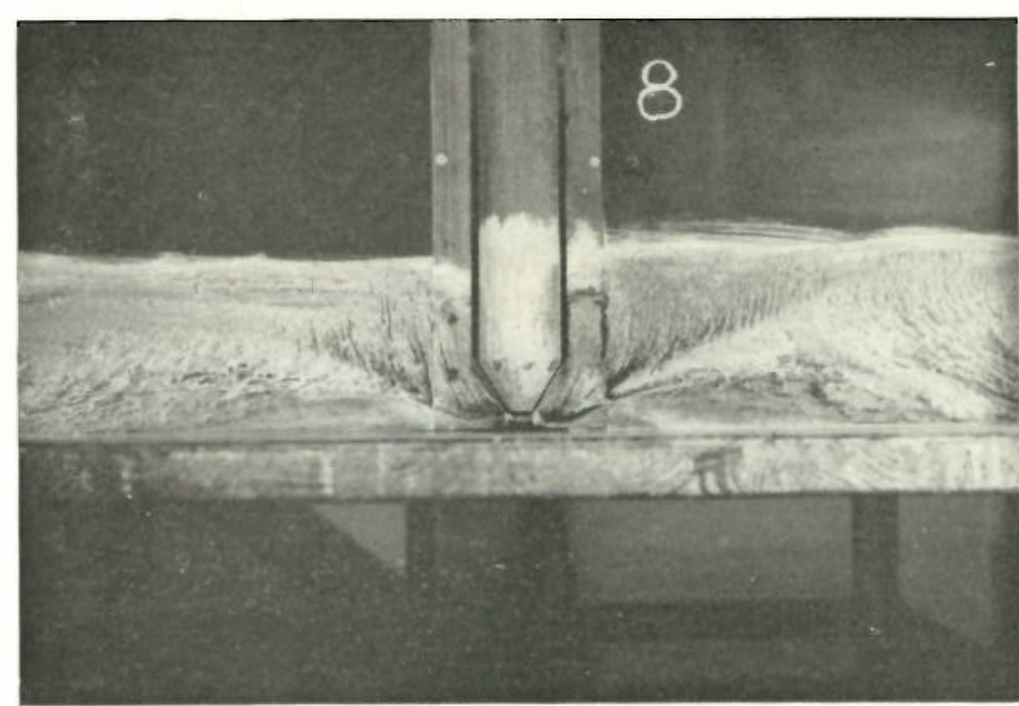


ment technique, and by various flow visualisation techniques $^{(\mathrm{T39}, \mathrm{T40)}}$. (Fig. 15).

\section{ROCKET RESEARCH}

Many fundamental problems in the field of rocket propulsion exist. The severe nature of these problems is shown by the number of large rocket launchings which are unsuccessful. The need for a rocket test bed was felt long ago at Cranfield, and in 1955 a rocket motor test bed to test rockets of up to $3,000 \mathrm{lb}$. thrust was brought into operation. So far the bed has been operated almost entirely with liquid propellant rockets, mainly a rocket of a type supplied by Napier's of $2,000 \mathrm{lb}$. thrust. This rocket uses hydrogen peroxide and kerosine as its propellant combination. It is a small rocket, 50 times smaller than liquid oxygen/kerosine motors currently powering some American rockets, and 500 times smaller than some rocket motors currently in development in the U.S.A. Though the Cranfield small rocket is used mainly for teaching purposes, it provides, nevertheless, the possibility of certain research in the field of liquid propellant motors. The motors have given evidence on the effect of combustion chamber length; the reduction in efficiency on making the chamber too short; the effect of varying the quantity of silver-plated gauzes used to decompose the hydrogen peroxide before its reaction with the kerosine; and the effect of deliberately lowering the injector efficiency. It became clear that the results of these investigations would have been more useful had it been possible to measure fluctuating rather than mean combustion pressures. A very useful pressure transducer was produced to measure these fluctuating pressures. The mean pressure on the transducer was backed off by high pressure nitrogen, so that the transducer element was exposed only to the fluctuating part of the pressure. By this means the transducer element, which was a strain tube, could be made more sensitive than was possible had it been required to withstand the whole full steady component of the pressure.

It is extremely difficult to detect the flow pattern of the reacting gases in a rocket combustion chamber. The combination of high pressure, often of the order of 500 p.s.i., and temperature (often of the order of $3,000^{\circ} \mathrm{C}$ ), makes the use of common visualisation and probing techniques impossible. The knowledge of flow patterns is, however, useful background information to the designer, who often considers changes in the injector system with a view to improving combustion efficiency or stability, or to decreasing the heat transfer to the walls of the combustion chamber. A successful method of investigating flow patterns within the combustion chamber, found at Cranfield, was the extension of the aerodynamic smear technique. A diaphragm of tungsten on a meridian plane dividing the combustion chamber into two was coated with a flame-sprayed zirconia (Rokide 2). Not only did this zirconia smear and thus indicate the flow directions, but colour contours on it were found which were thought to indicate contours of composition of reactants within the chamber.

Among other rocket work may be mentioned a theoretical investigation into the problem of high frequency pressure oscillations in solid propellant rocket motors. The investigation indicated that the burning rate of a solid propellant was likely to be very sensitive to high frequency fluctuations of gas pressure within the rocket, the sensitivity increasing as the frequency increased. A theoretical study is being undertaken of rocket engine operation and design to meet a wide range of specifications with minimum vehicle mass. Part of this work examined the problem of landing instruments softly upon the moon ${ }^{(60,61)}$.

\section{FUEL AND COMBUSTION RESEARCH}

The problems of the properties of fuel and their burning have led to a number of research investigations, which can be described under the following headings.

\section{Spontaneous Ignition}

An apparatus of the ASTM type, comprising a conical flask held in a bath of molten metal, has been constructed for the determination of spontaneous ignition temperatures of liquid fuels at atmospheric pressure. The conditions of the test are similar to those which would obtain at low altitude in a supersonic

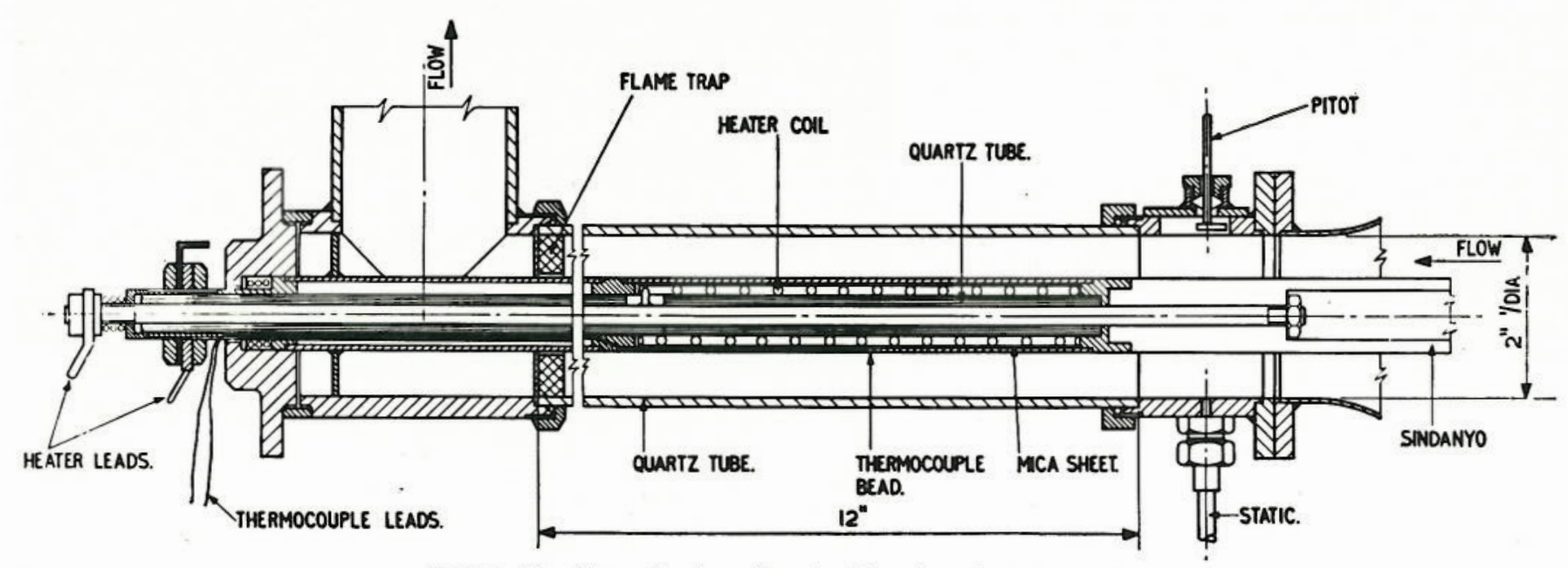

FIgURE 16. Atmospheric surface ignition flow rig. Test section. 


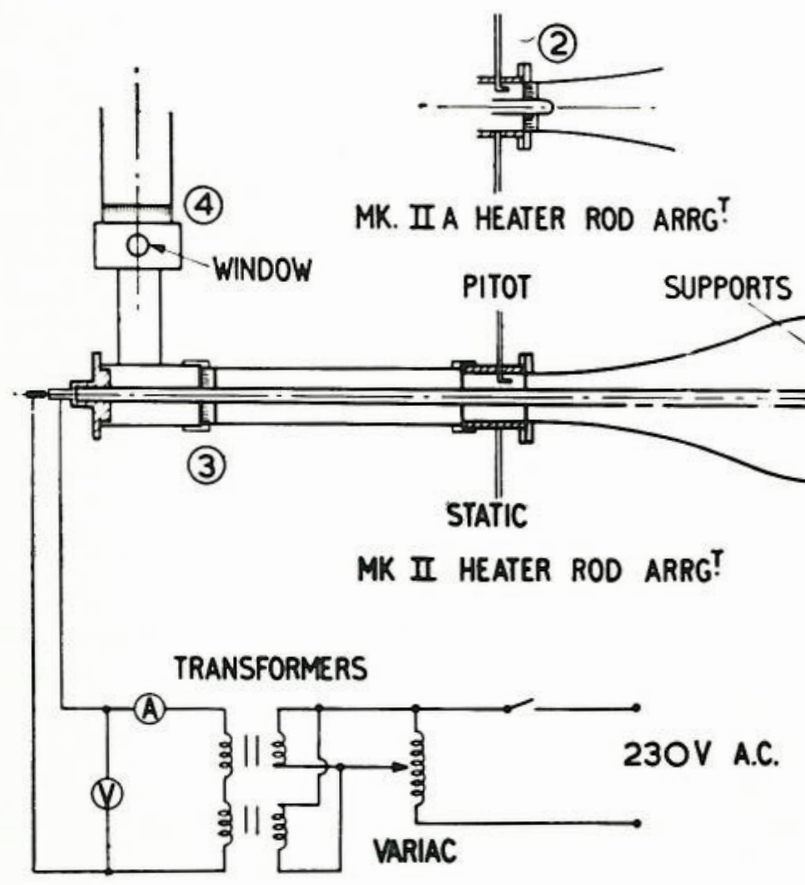

SURFACE HEATER CIRCUIT

aircraft fuel tank, or near an engine bay in an aircraft mainplane following leakage of fuel. As a routine measure, the relative ignitability of all fuels used in the Department is assessed by means of this test ${ }^{(62)}$. Work is in hand to improve the accuracy and repeatability of the test.

In spark-ignition piston engines spontaneous ignition is a factor controlling the onset of knock at the end of the combustion process. A particular form of spontaneous ignition, in which the mixture is ignited locally by means of a heated surface, is the factor controlling pre-ignition, which occurs at lower pressure at the beginning of the combustion process. To date, gasolines are rated solely on a knock basis, but the possible development of the pre-ignition problem with increased compression ratio emphasises the importance of preignition research, particularly since fuels behave very differently under these two conditions. Although engine tests are essential eventually, the results are complicated by three superimposed effects. These are the tendency of the fuel to form deposits, the tendency of the deposits to glow, and the tendency to ignition induced by these glowing deposits or by other overheated surfaces. In an attempt to separate these effects, a surface-ignition flow rig has been constructed in the form of a heated cylindrical surface located axially in a transparent cylindrical duct. Ignition takes place within a thermal, as distinct from an aerodynamic, boundary layer, and the results indicate the contact time, based on the free stream velocity, associated with the surface ignition. Certain pure hydrocarbons, of high ignitability, have been tested at atmospheric pressure. Surface temperatures in excess of about $910^{\circ} \mathrm{C}$ are found necessary to initiate ignition with a "free stream" contact time of $25 \mathrm{sec}$. or less. It has also been found possible to derive the temperature of the first element of mixture to ignite
FIGURE 17. Atmospheric surface ignition flow rigs. Location of flame traps. 
have been designed at Cranfield to constrain the flow direction over the heated surface, and so improve the repeatability. Previous experience had shown that normally aspirated engines needed heated pre-ignition units, whereas in supercharged engines the unit needed cooling. These requirements were not found in the normally aspirated engines at Cranfield, and a composite pre-igniter has been designed with provision for both heating and cooling ${ }^{(63)}$. Problem $(b)$ has been investigated further, and it is seen that pre-ignition is first aggravated and then suppressed by a continuous increase in engine speed ${ }^{(64)}$.

Flow tests have been carried out in a nozzle to investigate the possibilities of ignition by means of a strong shock wave. Highly ignitable fuels have been used, but without success ${ }^{\left(\mathrm{T} 41, \mathrm{~T}_{42}\right)}$.

\section{Flame Stabilisation}

Following a suggestion by Professor D. B. Spalding, combustion tests have been conducted with $\frac{3}{8}$ in. diameter rod stabilisers of porous stainless steel fed internally with kerosine at low pressure. Low blow-out velocities and tendencies to carbon deposition led to the design of a stalled cascade of porous aerofoil sections located in a wind tunnel equipped for operation up to 3 atmospheres. Preliminary results show performance to be poor under laminar flow conditions, and little better at high incidence. Subsequent work will include investigations of alternative geometries of greater degrees of bluffness ${ }^{(65,743)}$.

\section{Special Fuels}

The performance of a gaseous hydrogen-oxygen rocket motor has been investigated, over an $\mathrm{O}_{2} / \mathrm{H}_{2}$ mass ratio of 3.5 to 18 (stoichiometric ratio, 8). A system has been designed to handle these propellants in the liquid phase $\mathrm{e}^{\text {(T44, T45). }}$.

Work with aluminium-kerosine slurries has shown the optimum concentration of a gelling agent and a surface-active agent. A simulated reheat rig has been built, but further work on slurries may be centred on magnesium in view of the deposition difficulties ${ }^{\text {(T46, T47) }}$.

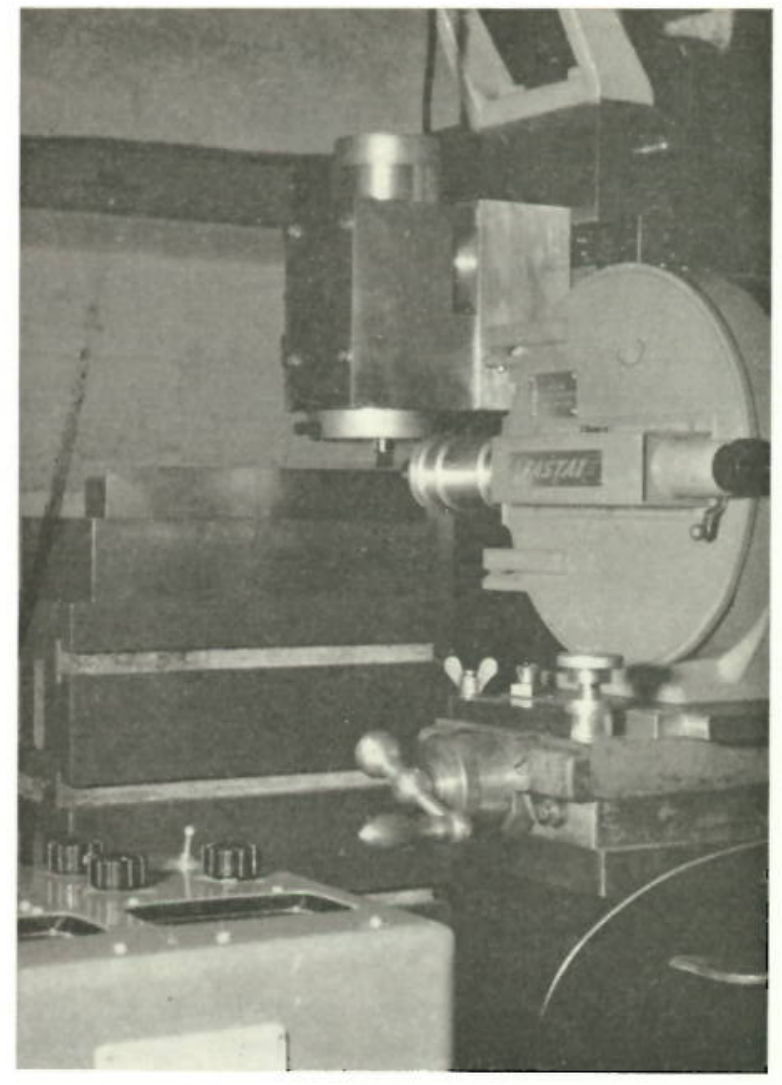

Figure 19. Investigation of plastic flow and final rupture.

\section{Department of Aircraft Economics and Production}

This country has been slow to appreciate the benefits which can be obtained from the application of detailed scientific investigation into production processes. Significant changes have taken place during the past decade, and the attitude of the Universities, the Colleges of Technology, the professional institutions, and many of the leading engineering industries is now distinctly encouraging. The Department of Economics and Production of the College is taking its part in these
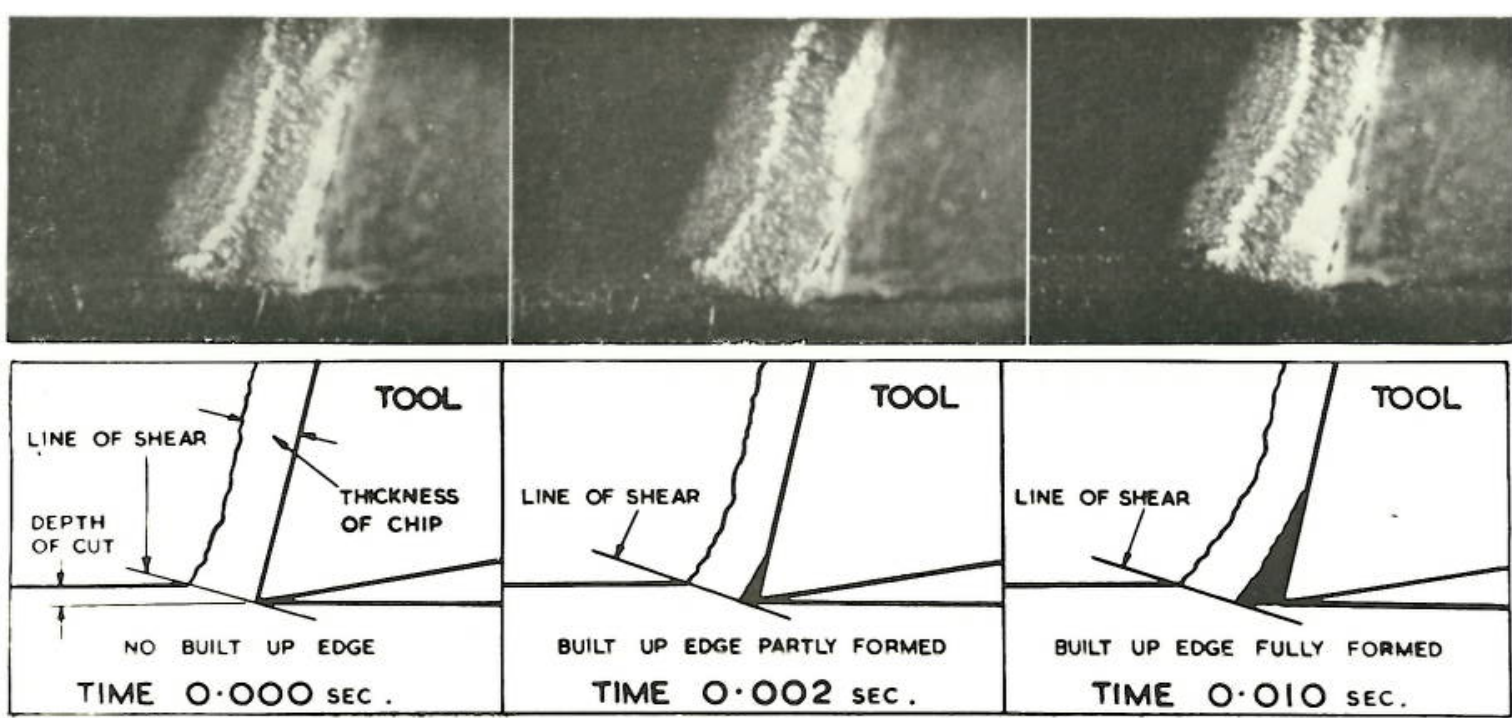

FIGURE 20. Formation of a builtup edge on face of tool. 
Figure 21. Principle of mechanical operation of cutting tool dynamometer.

developments and examples from its research programme are discussed.

The arrangement used for investigating the plastic flow and final rupture of material during a normal machining process is shown in Fig. 19. and Fig. 20 is a section of a film taken on the equipment where the machining speed was 60 ft. $/ \mathrm{min}$., film speed 2,000 irames/sec. and exposure time 4 microseconds / frame. This section of film illustrates the formation of a built-up edge on the face of the tool, a phenomenon which occurred on three separate occasions during a test run of less than one second. This type of data is supplemented by simultaneous and accurately synchronised high speed recordings of the magnitude, direction and sense of the three components of the force acting on the cutting tool during the experiment. The cutting tool dynamometer used is a development of a commercial instrument and was designed and manufactured in the Department with special consideration being given to the production of a device with very low hysteresis losses and a very high natural frequency of vibration. The instrument section of the Electrical Department of the College designed and manufactured the three electrical measuring elements, illustrated in Fig. 21, and the electronic equipment used for connecting the output from the instrument to five channels of a standard six channel high speed recording cathode ray oscilloscope. When the optimum tool shape has been developed, supplementary experiments are likely to provide reliable information on optimum speed and feed for a predetermined tool life and this type of data is likely to become of increasing importance with the development of tapecontrolled machine tools. One especially interesting investigation has been the development of a milling cutter to carry out the final machining operation on high tensile steel parts which have distorted during the final heat treatment operation.

Research is also being carried out in the recently organised High Precision Laboratory and is providing results which will enable a new assessment to be made of the total costs of manufacturing highly accurate mechanisms. Detailed analysis into so-called high precision equipment frequently reveals that many of the component parts are in themselves of relatively poor geometric shape and the high precision is confined to the relative size of one part referred to another.

One section of the research is directed to the manufacture of parts of good geometric shape and accuracy of size. When this condition is satisfied the parts comprising an assembly can be carefully fitted together without any adjustment in the size of one part to make it suit the size of another. The total cost of manufacturing a complete mechanism on this basis can be less than manufacturing the equipment from inferior parts because the slightly increased cost in producing the high precision parts is less than the cost incurred in adjusting one part to suit another.

As an example of the standards of accuracy now being attained, a shaft $1 \mathrm{in}$. in diameter and $4 \mathrm{in}$. long can be ground to an accuracy of ten millionths of an inch $(0.00001$ in.). This British machine is housed in the High Precision Machine Tool Laboratory of the College where automatic control is applied to the temperatures of the room, the cooling liquid, the hydraulic oil and the lubricating oil. The finish grinding cost is about 30 per cent higher than the cost of grinding the same shaft to a tolerance of one thousandth of an inch (1,000 millionths, 0.001 in.). Since this final grinding operation accounts for only about 20 per cent of the total manufacturing cost, the increase in the total cost is only 6 per cent.

The techniques being developed, with the support of the machine tool industry, are applicable to parts made as single components, small batch quantities and mass production.

Supporting mathematical work by statistical analysis has been carried out in the Department on the effect of the fit produced by the random assembly of parts made to predetermined tolerances.

INVESTIGATION INTO THE RELATIONSHIP BETWEEN MAN HOURS REQUIRED FOR THE MANUFACTURE OF AERO ENGINES AND THE NUMBER OF ENGINES MANUFACTURED

It is generally known in the Aircraft Industry that a relationship exists between the man hours $(y)$ required to manufacture a particular aircraft, of the form $y=a x^{-b}$, where $x$ is the serial number of the particular 


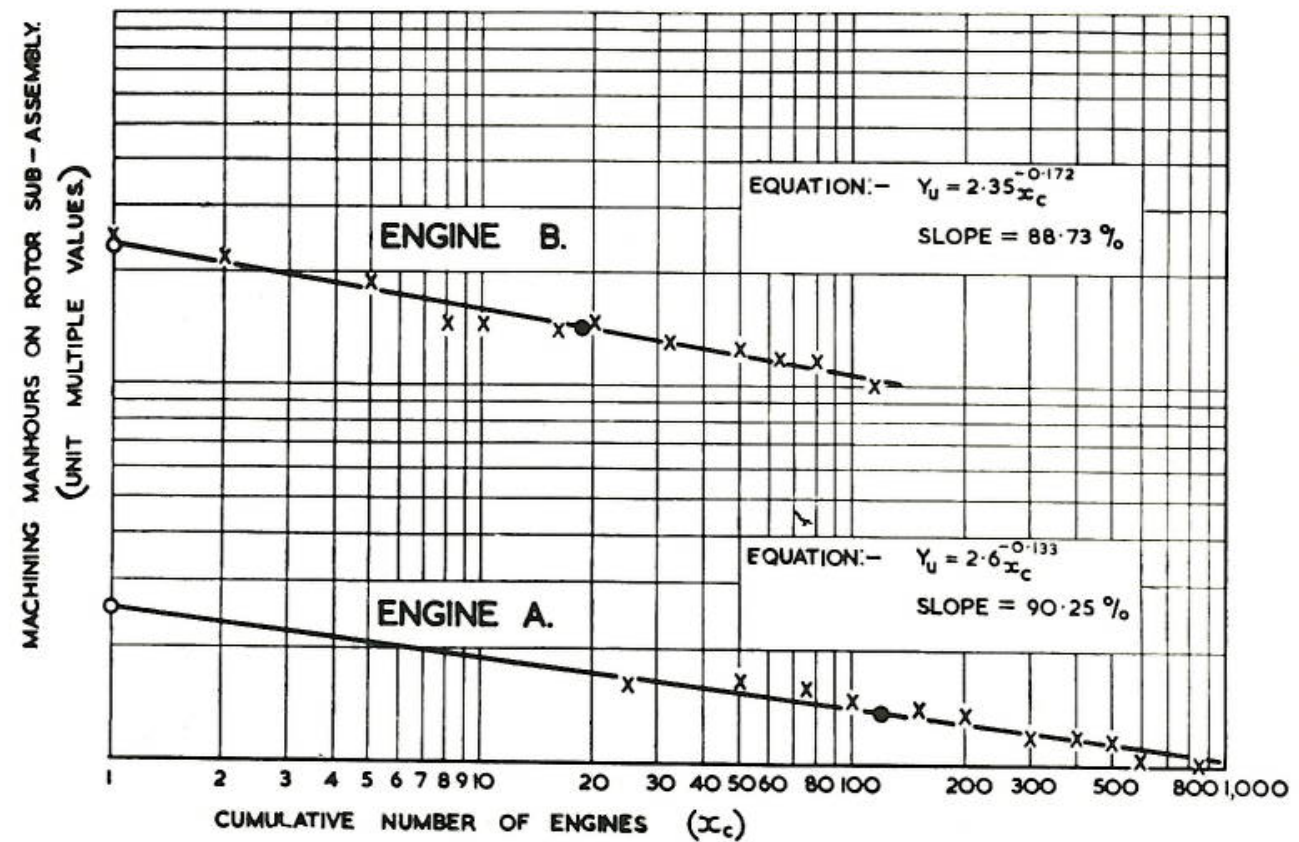

FIGURE 22.

by visual observation has presented serious practical difficulties. Investigation at the College has shown that these difficulties can be avoided by photosampling techniques of recording and analysing the methods of performing industrial operations by groups of work people. Instead of a number of work study observers, a ciné camera is used, actuated by a pulsing device. Exposures are made at each pulse and the time interval between pulses may be fixed at from 1 to $10 \mathrm{sec}$. depending on the nature of the work being studied.

One of the interesting features aircraft, and $a$ and $b$ are constants. One common form when $b=0.32$ is characterised by the simple relationship that the number of man hours required to manufacture the $2 N$ th aircraft is 80 per cent of the man hours required to manufacture the $N$ th aircraft.

Little is known of the corresponding relationships for aero engines, and for machining as distinct from assembly. Investigations conducted at the College on data related to some modern aero engines indicate that the slope for machining operations approximates to 90 per cent, and for assembly man hours 84 per cent. Figs. 22 and 23 show the data plotted on log-log scales.

\section{DEVELOPMENT OF PHOTO-SAMPLING TECHNIQUES FOR THE} STUDY OF LARGE WORKING GROUPS

The work study of large groups or teams of workers

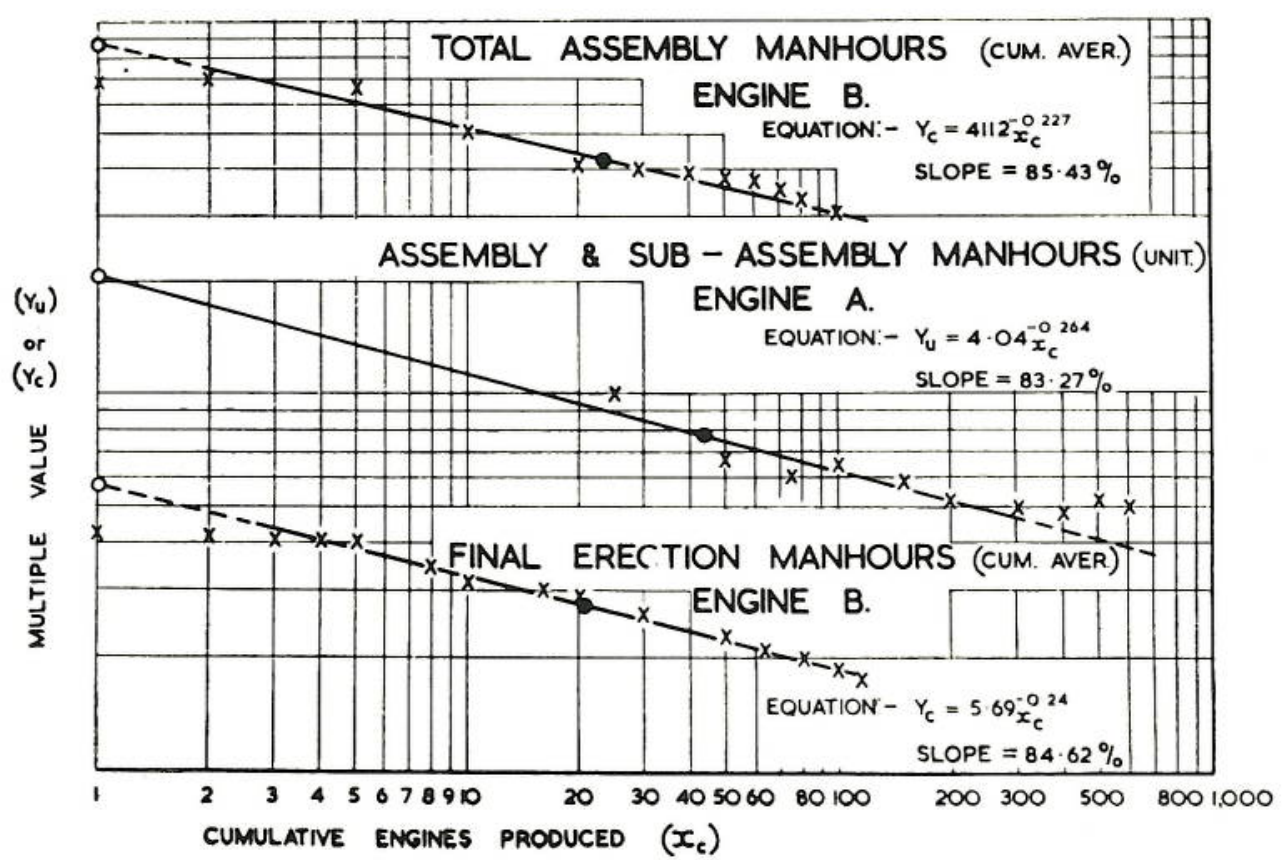

of this research has been the construction and use at the College of a random interval pulse machine. This machine provides pulses to an electrically operated camera at random intervals and from the subsequent analysis of the film, ratios of the component elements of the work can be evaluated. To facilitate the exact identification of the work being performed each randomly spaced pulse triggers a mechanism which operates the camera for a few frames at $\frac{1}{2} \mathrm{sec}$. intervals. Some of the equipment necessary for this technique is now becoming commercially available ${ }^{(\mathrm{T} 48-50)}$.

\section{OPERATIONAL RESEARCH}

In the field of stock control, research is being carried out on the effect of variable delivery times and variable usage rates on the probability of running out of stock. It is hoped from this research to develop a simplified method which can be used by industry to achieve a much greater degree of control without appreciably changing the capital tied up.

Activity sampling, using complex statistical and operational research techniques, is extensively used in Work Study. It has recently been suggested that this technique is often misapplied. The College is at present engaged in research in an attempt to develop a more efficient method of sampling. Such a technique has now been developed and is in the process of being tested both under laboratory conditions and in 
actual industrial applications. The methods developed will be introduced into the teaching of the Department and of the Work Study School.

In addition to these applied research fields a long term research programme on the factors affecting human reaction time to various stimuli has been started, the work being done jointly by the Department and the Work Study School. To date it has allowed the establishment of an operator's reaction to a light stimulus and has led to the measurement of changes in his reaction time when he is asked in addition to make decisions. It is hoped from this research to establish the relationships between factors which affect reaction time.

\section{STATISTICAL RESEARCH}

Using a hole and a shaft as specific examples, a statistical study has been made of the effect, on the extent of rejection or acceptance, of making parts when these are based on either, $(a)$ separate limits on the parts themselves at the manufacturing stage, or $(b)$ clearance limits representing the combination of those of $(a)$, at the assembly stage. Two types of distribution of part sizes, the normal and rectangular, are considered over the range of possible manufacturing precision and comparison made at a specific level using Standard Tables. Mathematical and Monte Carlo procedures are revealed and economic considerations treated ${ }^{(66)}$.

\section{Department of Aircraft Electrical Engineering}

The Department was established in 1955. Before this date there were limited facilities in electronics, machines and radio and radar in Design Department. Since 1955 the Department has grown rapidly as regards both Staff and equipment. It is divided roughly into electronics and physics, radio and radar, machines and power systems, and control and computation, the latter being the strongest. At first the attention of the staff was concentrated mainly on the establishment of laboratories and new courses, but lately some schools of research have taken shape. The first school, beginning before 1955, was in network theory and this continues to maintain interest. The largest school is in computer techniques, particularly in those which combine the advantage of classical analogue and digital methods. A third school, in microwave techniques, is concerned with the difficult problem of measuring the currents induced in irradiated sheets. In the remaining fields research has been confined to the work of individual students.

It is to be expected that the amount of long term research undertaken and the results obtained will increase considerably, and the Department is well equipped for such work. There are now established laboratories concerned with servomechanisms, analogue computing, digital techniques, process control, electronics, U.H.F. and V.H.F. techniques, microwaves, motors, servo components and power systems.

\section{HIGH SPEED HYBRID DIGITAL ANALOGUE TECHNIQUES}

(Refs. 67, T53, T61-T63)

The two basic types of computer in general use are the electronic digital machine and the electronic analogue machine. Essentially the digital computer does sums in simple discrete steps (digits) whereas the analogue computer draws a graph and uses continuous variables. The accuracy of a digital computer can be made as high as desired at the expense of a lower computing speed, since each digit movement occupies a certain time interval. Generally the speed is too low for operation in real time simulation of systems involving physical components and human operators. The digital computer is extremely versatile since it permits the problem to be split into a large number of simple arithmetical operations.

Analogue machines are much faster and can operate in real or even speeded-up time. The accuracy, however, is restricted to that of the physical components. Such machines also lack versatility because integration can only be performed with respect to time.

A new kind of computer has recently been introduced, termed the digital differential analyser, in which the individual mathematical operations are performed in a digital manner in discrete blocks, but in which the latter are interconnected to represent the particular mathematical model in a way similar to that employed in an analogue machine. The basic idea of this machine is an attempt to combine the accuracy of the digital machine with the high speed operation of the analogue machine. Developments in this field are mainly aimed at increasing the computing speed of the digital integrator which performs the operation $\int y d x$ where $y$ and $x$ are variables.

Work at the College has been mainly devoted to an alternative approach, particularly with regard to problems in which computing speed is more important than accuracy. The fundamental object of the method is again to perform the mathematical operation $\int y d x$ and so to remove the limitation of the conventional electronic analogue machine. Hybrid analogue digital techniques are used, however, to retain computational speed at the expense of accuracy. $\int y d x$ is obtained from the indirect operation $\int_{0}^{t} y \frac{\partial x}{\partial t} d t$. One variable $x$ is quantised by using one of several types of pulse modulation to give $\partial x / \partial t$ and the latter is multiplied by $y$ in a pulse modulator to give $y(\partial x / \partial t)$. The integration with respect to time may then be carried out with a conventional analogue integrator or a digital integrator.

Theoretical assessment and construction of prototype versions of a quantiser and a high speed digital adder have been the subjects of two student theses. Further work will be carried out on problems concerned with the pulse modulator and with the operation of the complete integrator. The provision of such units will considerably ease the problem of simulating non-linear systems, on a real time basis.

\section{MODULATED CARRIER FEEDBACK CONTROL SYSTEMS}

(Ref. 64)

The extension of root locus techniques in the design of a.c. servo-mechanisms is under investigation. Universal charts giving limits of possible performance have been compiled for simple systems. The feasibility 
of obtaining root and phase angle loci by automatic computing aids is also being considered.

\section{OPTIMUM DESIGN OF CONTACTOR SERVO-MECHANISMS}

A theoretical investigation of the optimum design parameters for contactor servo-mechanisms has been undertaken. Initial consideration is being given to the determination of predictor networks to enable the system to perform the particular task in the minimum possible time when subjected to simple types of input signals. Simulator studies of particular systems are also in progress.

\section{BOOLEAN ALGEBRA (Ref. T66)}

The mathematical expression of logic proposed originally by George Boole in 1847 has been the subject of considerable study since 1939, this interest having been aroused by a realisation of its applicability first to telephone switching problems and later to the systematic design of digital computers. By its use the solution of such problems is largely removed from the realm of experience and intuition.

The basic principles of the algebra are very simple but when used to describe the possible configuration of $n$ switches the number of expressions generated is a double exponential $\left(2^{2 n}\right)$ and one of the chief preoccupations of writers in this field has been the simplification of these large numbers of expressions so that when translated into hardware a minimum of components need be used.

All the most important methods of simplification have been systematically studied at Cranfield and a new method has been proposed which is more easily applicable than the others when $n$ is greater than about 5 . Clarification and extension of the present concepts of geometrical representation in $n$-space of the Boolean expressions has been carried out, as well as exploratory work on two distinct forms of matrix which promise to be of importance in the study of another outstanding problem, that of the $a b$ initio synthesis of switching networks, especially those incorporating time delays.

Other topics touched upon are the modification of the algebra to encompass undirectional switches (i.e. rectifying elements) and the possibility of reducing all

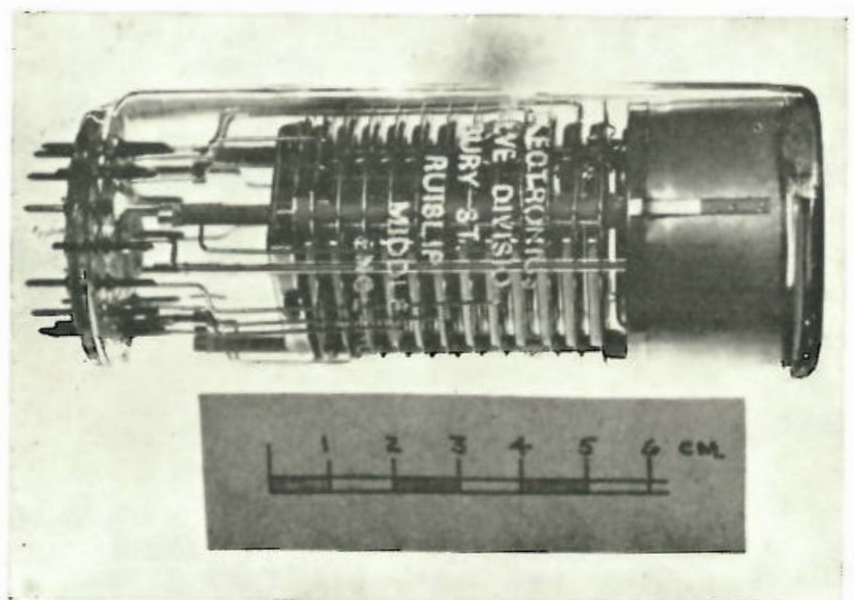

FIGURE 24. Grid controlled photomultiplier. problems to the study of a limited number of "symmetric switching functions" which may be constructed so as to imply all the remaining functions of interest.

A GRID-CONTROLLED PHOTOMULTIPLIER (Ref. T52)

It has been known for some time that very high voltage gains could be obtained from single thermionic valves by incorporating a system of secondary emission electrodes so as to multiply the original current (and its fluctuations) by factors as high as $10^{6}$. This investigation was carried out to discover whether a photoemissive cathode could be substituted for the more usual thermionic emitter and what advantage, if any, might accrue (Fig. 24). Various kinds of illumination were used to excite the photo-cathode, whose emitted electron current was controlled as in a conventional valve by the potential on an adjacent grid. Light of various wavelengths and a scintillator energised by a strontium 90 source were all tried. Direct injection of electrons from the strontium 90 without the intermediary of a scintillator was not satisfactory. Limitations of power dissipation have necessitated a pulsed method of operation to achieve the order of transfer conductance expected, but up to the present time shortcomings in the physical structure of the available tube has limited the transfer conductance to about $70 \mathrm{~mA}$. per volt compared with about $10 \mathrm{~mA}$. per volt for a conventional high- $g_{\mathrm{m}}$ thermionic valve.

\section{SOME TRANSISTOR APPLICATIONS}

(Refs. 68, 69, T53-T55, T66, T68)

The relatively recent surface barrier transistors have been used in an attempt to achieve very high speed adding in digital computers. A parallel mode has been employed and the carry propagation time for a digit binary addition has been reduced by the combination of a novel form of logic and the fast transistors to 1.0 $\mu$ second. The total addition time is $3 \mu$ seconds, a figure so far substantially superseded only by circuits using the newer and very expensive micro-alloy transistors ${ }^{(T 53)}$.

The possibility has also been investigated of using a transistor to detect very small degrees of motion. A

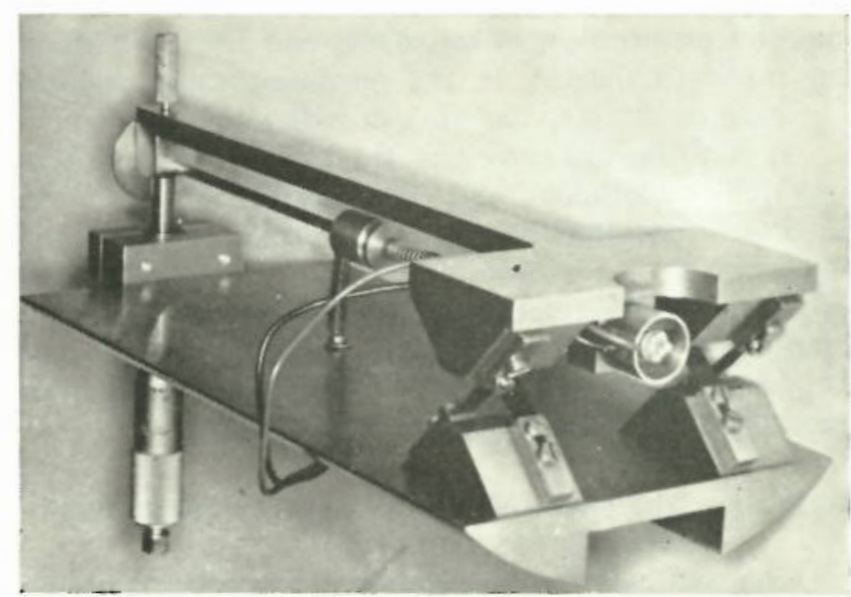

Figure 25. Relative motion mechanism. 


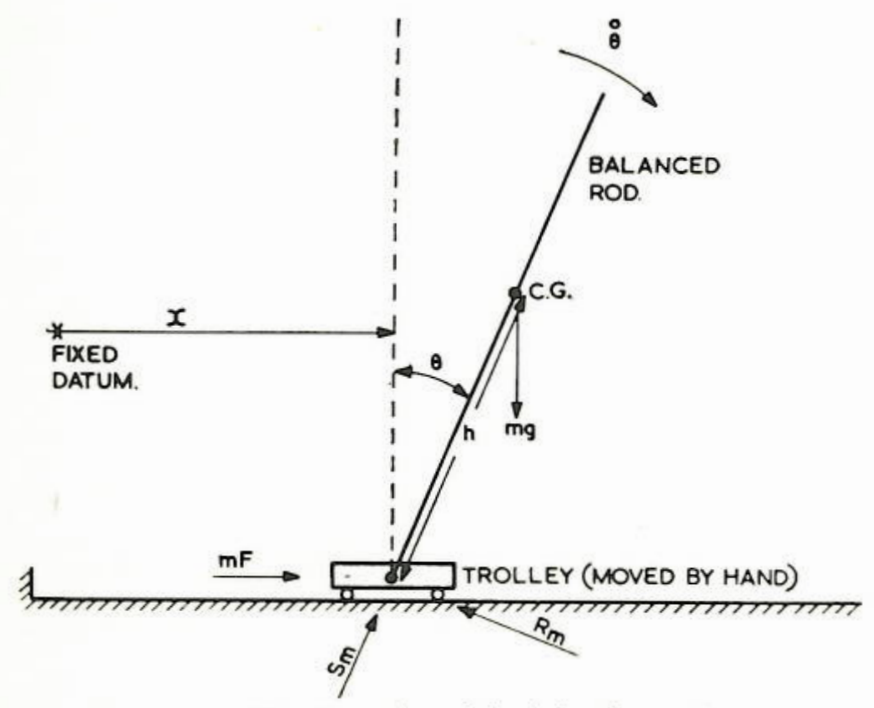

FIGURE 26. The dynamics of the balancing system.

$p$ - $n$ junction is subjected to a beam of $\alpha$-particles and emits pulses which may be counted. Small displacements of the very small sensitive area relative to the beam result in changes of the count (Fig. 25). The results suggest that, with modifications, displacements of 0.00015 in. could be detected by counting over a period of $25 \mathrm{sec}$.

The phenomenon of hole storage in a saturated transistor has been put to use in the design of a simple and economical pulse width modulation system suitable for missile and aircraft telemetry. The hole storage time is governed by the base input current which in turn is a function of the variable to be telemetered. An accuracy of 3 per cent with inputs in the range 0 to 1 has been achieved.

VARIATION OF YOUNG'S MODULUS WITH TEMPERATURE

(Ref. 70)

Accurate measurements of Young's modulus at temperatures between $20^{\circ} \mathrm{C}$ and $1,000^{\circ} \mathrm{C}$ have been made for all the Nimonic alloys by a magneto-strictive method which detects the change in the delay time of a stress pulse travelling along a wire of the material under test.

\section{THE TRANSFER FUNCTION OF A HUMAN OPERATOR} (Ref. T56)

There have been many attempts to measure the characteristics of the human operator. The study of his behaviour in performing some task of control may be vital, particularly in relation to certain aircraft pilot and missile command link systems. It was desired to devise an experiment which would be sensitive to the form of the human transfer function under chosen conditions. The experiment designed to meet these requirements takes the form of a rod which has to be balanced on end. In this the operator is forced to a high degree of concentration to perform a pleasant and amusing task and the risk of vitiation of the test through boredom is diminished. To provide a consistent and manageable experiment the rod is pivoted to constrain rotational movement to one plane only on a carriage which moves

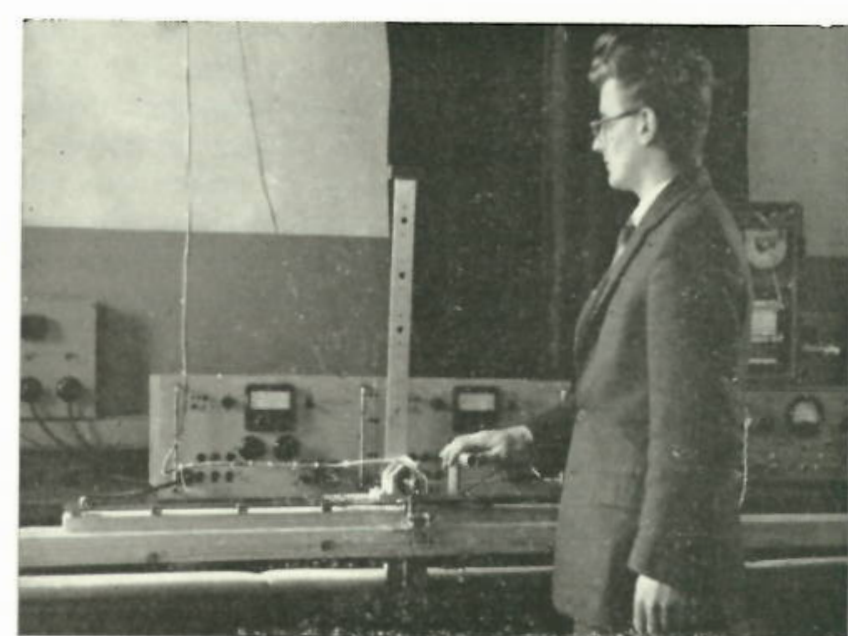

FIGURE 27.

to and fro on a track in the same plane (Figs. 26 and 27). On suddenly freeing the carriage and rod from constraint in the position of unstable equilibrium, recordings are taken of the angular motion of the rod and the linear travel of the carriage while the operator maintains the rod in a state of balance. By analysing the waveforms generated by the operator plus system during the time he is maintaining balance it is hoped to determine some significant parameters concerning his response. Preliminary tests have confirmed the feasibility of the method, and have shown that the accepted approximations to the human transfer function are not adequate to describe the performance of this task.

\section{ELECTRIC NETWORK THEORY}

(Refs. 71-72, T57-T60, T68)

The two fundamental problems of network theory are analysis and synthesis. Network analysis is the determination of the response when the network and excitation are prescribed; network synthesis is the determination of the network when the excitation and response are prescribed. Both problems have received attention at Cranfield.

Recent developments in network analysis have led to a systematic process which is both powerful and flexible. The mathematical basis to this new approach is a combination of matrix algebra and the combinatorial topology of linear graphs. Most of the work in this field has been confined to the study of networks in the sinusoidal steady state but at Cranfield the method has been extended to include network response in the time domain and to include the case of networks containing active elements such as thermionic valves and transistors.

The problem of network synthesis has three aspects: approximation (the determination of a physically realisable function which satisfactorily approximates the desired network behaviour); realisation (the determination of a network corresponding to the given approximant); and equivalence (the determination of all networks electrically indistinguishable but structurally different from a given realisation). Each of these aspects has been the subject of students' theses. Two graphical 
techniques have recently been devised to facilitate approximation; a procedure for synthesising single energy 2-port networks according to prescribed driving point and transfer functions has been proposed; a method for synthesis according to prescribed time response has been developed; and an attempt has been made to generalise the Howitt-Burington theory of equivalence to yield equivalent networks with different kinds of elements.

\section{SURFACE CURRENT MEASUREMENT (Refs. T69-T71)}

A general interest in suppressed aerials in 1955 developed into an interesting programme of basic research into the measurement of radio frequency currents in metal surfaces.

The notch aerial in its simplest form is an openended slot cut into the edge of a metal sheet. This is an attractive proposition as an aircraft aerial; it can be cut into the edge of a stabilising fin and covered with a dielectric so as to present the external contour required by the aerodynamicist. When this aerial is excited, current can be driven through the skin, and the whole aircraft can be likened to a flying aerial.

Knowledge of the current distribution around a notch was only available for the impracticable case of an infinitesimal notch cut into a semi-infinite sheet; other conditions of notch are not amenable to analytical treatment. The initial problem was to develop a current measurement system and to investigate the distribution about a finite slot cut into a plane sheet of finite dimensions.

A convenient sheet of dimensions $122 \times 244 \mathrm{~cm}$. was used and slots were cut into the centres of the broad and narrow sides; slot depths investigated extended to some $18 \mathrm{~cm}$. The energising transmitter produced some 100 watts at $180 \mathrm{~cm}$. wavelength.

The surface currents were detected by a hand probe based on a loop aerial; the elimination of stray pick-up was a severe problem and the loop was made as small as possible so as to indicate more nearly the current at a point on the surface. The final loop design is shown in Fig. 28. The loop diameter of $1.3 \mathrm{~cm}$. $(0.00725$ wavelength) is considered to be the smallest practicable size

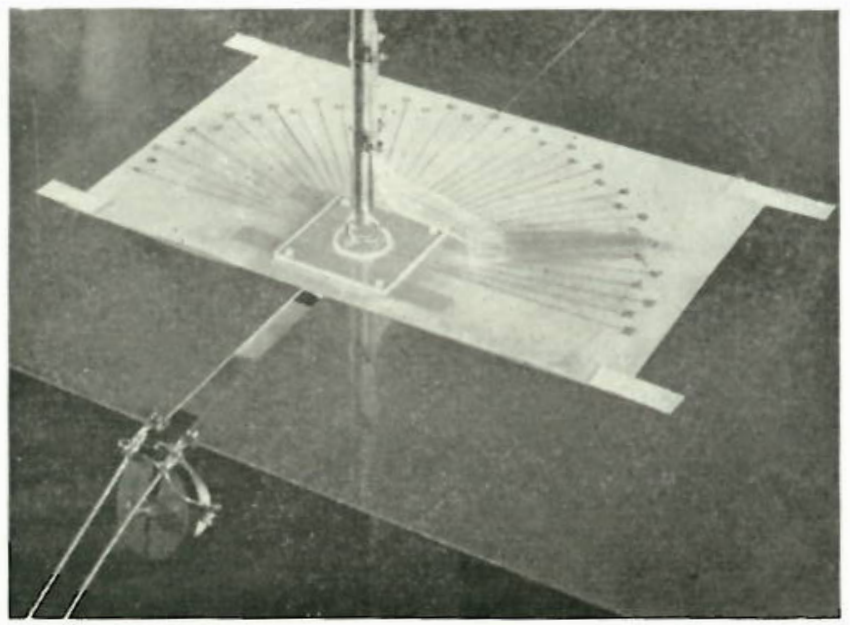

Figure 28. Pick-up loop.

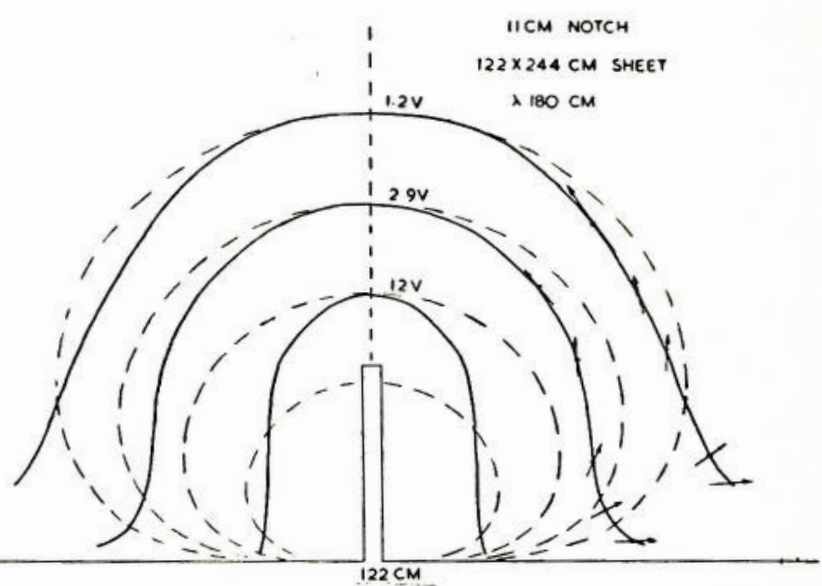

Figure 29. Current contours measured round an $11 \mathrm{~cm}$. notch.

capable of yielding useful information in this type of work. Fig. 29 shows, in solid line, the current contours measured around an $11 \mathrm{~cm}$. notch, arrows showing the direction of current flow, and the broken line the theoretical current contours on a semi-infinite sheet. The effect of the finite size giving rise to currents flowing parallel to the edge can be seen clearly and if the length is resonant at the applied frequency then high standing waves can exist on this edge and efficient radiation of energy can occur.

Some success having been achieved with the energised sheet, attention was turned to the measurement of currents induced in a sheet when irradiated by an electromagnetic wave. A knowledge of the induced current distribution would lead to a better understanding of the phenomenon of electromagnetic scattering by conducting bodies of complex geometry. The main interest is in bodies whose dimensions are several wavelengths long, so for experimental convenience work was carried out at wavelengths of 3 and $10 \mathrm{~cm}$.

At these wavelengths a loop aerial of the smallest practicable dimensions (some $1 \frac{1}{4} \mathrm{~cm}$. diameter) would be responsive to too great an area of surface (in terms of phase) and it was considered that better results could be obtained by other methods. In consequence measurements were made using a re-radiating probe and a slotted line.

The re-radiating probe takes the form of a movable unipole aerial capacitatively coupled through its base to the conducting surface and radiating a wave having a quadrature polarisation to the incident waves. The slotted line is a coaxial line constructed within $\frac{1}{2} \mathrm{~mm}$. bore hyperdermic tubing short-circuited at the remote end with a single transverse slit pick-up cut near the short circuit. The line is placed on the surface, so causing the inner conductor to be inductively coupled to the sheet through the slit. Present work is devoted to obtaining a "standard" surface having a known induced current distribution. As soon as a mechanically realisable standard is determined a comparison apparatus will be developed to investigate the various possible forms of pick-up devices to ascertain the accuracies achievable in both the magnitude and phase measurement of induced currents. 
HYSTERESIS MOTOR (Refs. T72-T75)

The hysteresis motor is unlikely to be a competitor of the more widely used a.c. motors for general applications, but its unusual characteristics make it very suitable for certain drives such as gyroscopes in guided missiles. Little has been published on the theory, although the mechanism of torque production at speeds between standstill and synchronism has been understood for some time. The objects of this further work were:-

(a) to establish design criteria for the rotor material and air gap structure and configuration,

(b) to examine the performance near synchronous speed with regard to establishing the mechanism by which synchronism is achieved by the rotor,

(c) to examine the effects of harmonics on the airgap field distribution,

(d) to examine the significance of the eddy current torque on hysteresis motor performances.

From a purely theoretical standpoint, eddy currents are extraneous to an investigation of hysteresis motors, as also are air-gap field variations. However, since the hysteresis torque is proportional to the volume of magnetic material in the rotor, and the eddy current torque is proportional to the surface area of the rotor bounding the air-gap, only in large machines will the eddy current torque be negligible. Thus it is necessary to study the combined effects.

Analysis of the relationships between the time and circumferential variations of flux density and applied magnetomotive force leads to results which are similar to the torque equation as derived by Teare, but in a much more useful form. Fourier analysis applied to the $B-H$ integral thus obtained indicates that the hysteresis torque is dependent on three parameters, only one of which, (the space angle between the fundamentals of $B$ and $H$ ) is variable in any particular motor configuration. The method has been extended to establish the mechanism by which synchronism is achieved by the rotor. This involved solving the equation of motion of the rotor; although this equation is inherently nonlinear, a process of linearisation has allowed a solution to be obtained. This has been checked with a simulation study, and an experimental investigation has been undertaken to explore the transient performance of two different motors. Some difficulty has been found in measuring the transient values of the torque, and quantitative correlation with the theoretical expressions has not been attempted so far. The qualitative indications nevertheless support the theory developed, and work is proceeding to obtain positive experimental verification.

\section{TWIN 150 H.P. GENERATOR DRIVES}

In order to take part more effectively in the development of new aircraft electrical power systems, two electrically driven Ward-Leonard systems each of 150 h.p. have been installed and will shortly be commissioned. This power can be developed at any speed between 2,100 r.p.m. and 12,500 r.p.m., the value of speed being maintained constant within \pm 1 per cent of the selected value at any load between zero and full load.

\section{Department of Aircraft Materials}

The main researches in the Department at the present time are particularly related to the question of metal fatigue. In this context, work is being undertaken with the support of the Ministry of Aviation on the high strength aluminium-zinc-magnesium alloys, which have an unexplained low ratio of fatigue limit to tensile strength. There is a strong suspicion that this is in some way related to the characteristics of precipitation in these alloys, and one suggestion is that the action of the alternating stresses causes the precipitates, in certain very small localities, to go back into solution. These softened regions are then thought to be the regions in which the initial fatigue cracks are created.

The Departmental work has been concerned, in the first place, with studying the fatigue characteristics of such alloys when these are deliberately under-aged or over-aged by thermal treatments before the fatigue stressing is commenced: that is, the process of precipitation is initially either not developed at all or over-developed beyond the optimum state. In both cases the fatigue life is somewhat reduced for a given stress, but the fatigue limit changes very little. It is hard to see on this basis how the relatively low fatigue limit can be due to a re-solution mechanism in a small locality if the virtually complete solution of precipitates (by the inhibition of the precipitation process) has very little effect. This result does not, however, completely dispose of the re-solution hypothesis, which may still be the determining factor.

Attempts have been made to modify the nature of the precipitate distribution by stressing the alloys for short periods between the actual solution treatment and the ageing. Such periods of either alternating or static stress accelerate the rate of ageing and, in certain cases, actually make possible a greater final hardness than that achieved without such intermediate stressing. Whether this state is also one of better fatigue resistance is a question which is now being examined.

A great deal of work has also been carried out on the electrical resistivity changes which occur in the aluminium-zinc-magnesium alloys during ageing and fatigue. These results are a little complex to summarise in a short space, but emphasis may perhaps be placed on two points. Firstly, it has always been accepted that the rate at which precipitation occurs is directly related to the concentration of vacancies (on the atomic scale) in the metal. If this concentration is increased-as it can be by the kind of intermediate stressing already noted-then the subsequent rate of precipitation increases, as observed. This would also be expected to be true for the case where precipitation is actually occurring simultaneously with the application of an alternating stress. Measurements on electrical resistivity suggest that for these high strength light alloys, at least, the rate of precipitation is retarded. This is a quite unexpected result, and may well support the hypothesis that resolution occurs in these alloys under alternating stress, effectively delaying the opposite process of precipitation. These results are now being checked by comparison with the behaviour of other aluminium 


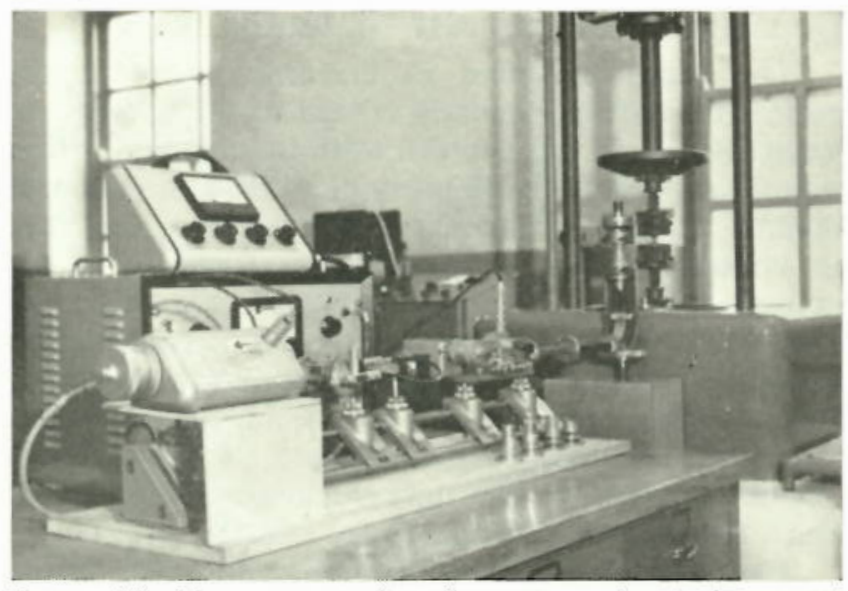

FigURE 30. Measurement of surface attenuation during ageing and fatigue. (The tubular test piece is shown mounted in grips, but disconnected from the fatigue machine.)

alloys which show good ratios of fatigue limit to ultimate stress, such as the 4 per cent $\mathrm{Cu}$ alloy.

A new technique has been developed and applied to the study of the surface changes that occur under fatigue. Basically, the method involves working with a test piece in the form of a wave guide, the change of attenuation of radio waves in the wave guide being measured during the course of fatigue (Fig. 30). While the technique in itself is not difficult in principle, the achievement of the required level of accuracy and reproducibility has involved a great deal of refinement and control. The actual attenuation offered by test pieces of practicable size (that is, a few inches long) is so small that changes in this attenuation are extremely difficult to measure with the required degree of accuracy. It is, however, hoped that measurements of this kind will be able to elucidate whether or not changes occur in such alloys very near to, or actually at, the surface (the depth of penetration of the microwaves is about one micron at the frequency used) even though the main bulk of the material is unaffected. This again relates to the re-solution proposition, which suggests that fatigue is initiated in very localised surface regions.

Other work of a more technological nature is concerned with the improvement of castings by the application of mechanical vibrations during the solidification process. Recent results on a steel (H.R. Crown Max) show that if the frequency of vibration is correctly chosen a finer and more uniform grain size is achieved with consequently improved mechanical properties. The tensile strength is raised from 40 to 45 ton. $/$ in. ${ }^{2}$, the elongation from about 30 to 40 per cent and the impact strength from $7 \cdot 5$ to $10 \mathrm{ft}$. lb. (Refs. 73 and 74).

New research lines are now being established concerned with the properties of beryllium, up to about $400^{\circ} \mathrm{C}$, and with the structural alloys of aluminium, magnesium and titanium under the conditions likely to be encountered at the skin of a Mach 2 vehicle. As it happens, both these projects raise fundamental issues in what is known as recovery, a general term which embraces a number of processes by which metals zecover, or tend to recover, their original properties after some kind of treatment, such as mechanical working. Stress relaxation is, of course, an obvious example of this type of behaviour. In the case of the Mach 2 skin materials these processes may be further complicated by special metallurgical changes associated with precipitation, and these may exert a serious influence on the way in which such materials may be utilised.

\section{Department of Mathematics}

During the past few years, some investigation of wave drag of bodies in supersonic flow has been carried out in the Department. This has led to the formulation of what is now known as the "transfer rule" for calculating the wave drag of winged bodies and the minimisation of this drag, and to a general method of dealing with drag calculations for both lifting and nonlifting bodies which has become known as the "harmonic method." In addition, methods for the numerical calculation of drag of slender bodies and of lift and drag of wings at supersonic speeds have been investigated ${ }^{(75, \mathrm{~T} 76)}$

Other topics which have received attention are wing-tailplane flutter, for which numerical computations have been made, and the development of special vector integral identities for the integration of vector differential equations. The Department has also carried out various small investigations for the benefit of other members of the College staff, including numerical computation in many cases.

In the future, it is hoped that the Department will engage in the development of computational methods and techniques for application in all branches of aeronautical engineering.

\section{Department of Flight}

The primary teaching subjects in the Flight Department are stability and performance with the associated problem of instrumentation for their measurement. This leads naturally to research in these two fields which lean heavily on the third for their solution. Aircraft available include a de Havilland Dove, a Morane Saulnier 760 and two Avro Ansons.

\section{STABILITY}

For a number of years work has progressed in the Department on the measurement of dynamic stability. The problem appears simple enough in that the motion of an aircraft can be expressed in terms of a set of simultaneous equations of the second order and it is only desired to find the constants of three equations. The method most widely used was developed by Cornell Aeronautical Laboratory and consists of a harmonic analysis of the control input function and of the resultant output in terms of aircraft response. In practice the results obtained by this technique, at the College, have proved moderately acceptable in the longitudinal mode but not at all satisfactory for the lateral modes. In fact many authorities have strong reservations about the validity of the analysis.

Because of this failure of the lateral tests a new technique has been tried which is much simpler to apply 
and makes greater use of the data obtained from flight tests. A primary characteristic of the lateral modes is the Dutch Roll Oscillation which is poorly damped on most aircraft. In such an oscillation the separate sums of rolling forces, yawing forces and side forces are normally equated to zero but, since the increments in each equation are not in phase, the most informative presentation is in the form of a force polygon using the maximum amplitude of the forces as modulus and their relative phase angles as direction.

From flight tests, the amplitude and phase angles of the variables (roll, yaw and lateral acceleration) are measured and all that is needed for a complete solution is to know the ratio of the derivatives. These are found from "steady state" manoeuvres such as straight sideslips, rates of roll and flat turns.

This technique for the measurement of lateral derivatives was in fact arrived at in reverse. An attempt was made to find the derivatives using the numerous "steady state" manoeuvres available in the lateral case i.e. straight sideslips, flat turns, turns on aileron only, etc. As might have been expected, these only give the ratios of the derivatives and some measure of frequency in the system is necessary to find their values in terms of the moment of inertia of the aircraft. This is where the vector presentation of the Dutch Roll has proved so useful.

Tests on the Dove have proved the method of analysis to be quite practicable and improvements are expected in the coming year by use of more sophisticated instrumentation. The aim from the beginning has been to avoid the use of estimated derivatives at any stage but to rely entirely on measured data. The system is to be used on the MS760 where there is the additional advantage that fuel can be used from one tip tank at a time giving a direct measure of the aileron rolling power -a key derivative in most lateral manoeuvres.

\section{PERFORMANCE}

Until the past few years almost all performance work has been done in straight and level flight, where the steady speed was measured against engine power using either the engine manufacturer's power curves or some torque measuring device. This technique is still taught in the Department but a need has been felt for an improved method making full use of the continuously recorded data instead of the present one of analysing a relatively few discrete points. The basis of the approach is that power (for a piston engine) and thrust (for a jet) remain almost constant with speed, whereas drag varies as the square of the speed and the square of the lift coefficient. Proceeding along these lines, it only seems necessary to vary the speed in an arbitrary manner by diving and climbing and to measure the aircraft's acceleration in the process.

Some preliminary tests have shown that the order of accuracy of instrumentation needs to be greatly improved and, until this is done, it is difficult to assess whether or not the method is practical. There are two methods available for handling the information. In one, high-speed read-out equipment can be used to measure numerous discrete points which would then be handled by a digital computer giving the best available fit for the material. A more elegant solution is to use a simple form of analogue computer in flight continually solving the speed and acceleration equation with an input of pitch attitude, best fit showing as an error between computed and measured speed. This type of system could be made self-regulating so that a proper statistical average of the drag characteristics could be obtained.

The continually increasing accuracy demanded of the instrumentation for dynamic stability work in the Department has led to the consideration of radical changes in the measurements of rates of roll, pitch and yaw. The conventional method has been to use rate gyros with precise damping characteristics. The resolution and the behaviour of the damping under flight environment leave much to be desired. The scheme suggested is to use free gyros for pitch, roll and yaw with digital pick-off in the form of Moire fringes giving accuracies of the order of seconds of arc. Rates can then be obtained, either directly or by subsequent laboratory analysis, using the time interval between pulses. The argument in favour of the free gyro is that its free wander rate is extremely low compared to the time interval of the dynamic flight manoeuvre and damping problems are eliminated.

Indeed the whole question of Flight Test Instrumentation must be carefully considered in view of advances in theory and in the systems of data handling. It is felt that the time has come to have a thorough investigation of present practice relating not only to the quantities measured but also to the accuracies of the final data. All too often vital small functions are concealed by frequency sensitivities, variable damping effects and calibration difficulties, and devices to overcome this must be developed. A typical example is the requirement for a three-axis accelerometer accurate to $0.03 \mathrm{ft} . / \mathrm{sec}^{2}$ with no cross coupling effects. The problem appears to have been solved in inertial navigation systems to orders of accuracy much greater than is asked for here.

The other problem is the recording of these data to the same order of accuracy. The present limitation is generally imposed by the paper width on trace recorders giving accuracies in the region of one per cent of full paper width, which, of course, is normally more than one per cent of full amplitude. This accuracy must be improved either by digital recording on paper or some other medium preferably in a form suitable for automatic data processing. It is hoped these problems will be enlarged upon in an Instrument Symposium in 1960.

\section{FURTHER CURRENT RESEARCH}

\section{Lancaster}

Tests on the Midge wing, (Fig. 31) mounted above the fuselage of the Lancaster, were successfully concluded in June 1959. The measurements on boundary layer transition due to sweep on this scale of model ( $8 \frac{1}{2} \mathrm{ft}$. span $\times 6 \mathrm{ft}$. chord) are proving useful in the design study of a swept wing for laminar flow. In addition the 120 pressure plotting points give a very 


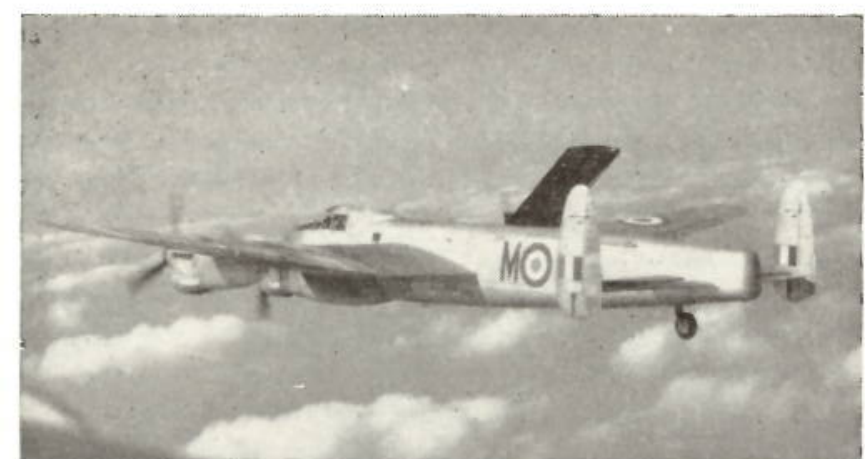

Figure 31. Lancaster with Midge wing on mid-upper fuselage.

detailed picture of the pressure distribution for comparison with theory ${ }^{(76,77)}$. The work on swept wings is to continue with a model designed to investigate the suction parameters necessary to maintain laminar flow. It will be mounted above the Lancaster and flying should begin early in 1960 .

\section{R.A.E. Thurleigh}

In the session 1959/60 a combined experiment was undertaken with Aero Flight at Thurleigh. The Department manufactured a number of outside air temperature probes (Fig. 32), each of different design, which were then fitted on a Hawker Hunter and flown from Thurleigh. The investigation was made to clear up some serious anomalies in the measurement of outside air temperature where characteristics appear to change with altitude ${ }^{(78)}$. The problem was completely resolved and the work has led to a new standard air temperature probe being adopted by the Ministry of Aviation.

It is hoped to continue this type of association with Aero Flight and it is proposed that this year a student should carry out a research programme on artificially induced buffet on a Venom.

\section{Short Sherpa}

Two years ago the programme of research on rolling response with all moving tips was brought to a premature end due to an engine failure. Both engines have now been modified and the programme on rolling response will continue during the present session. There

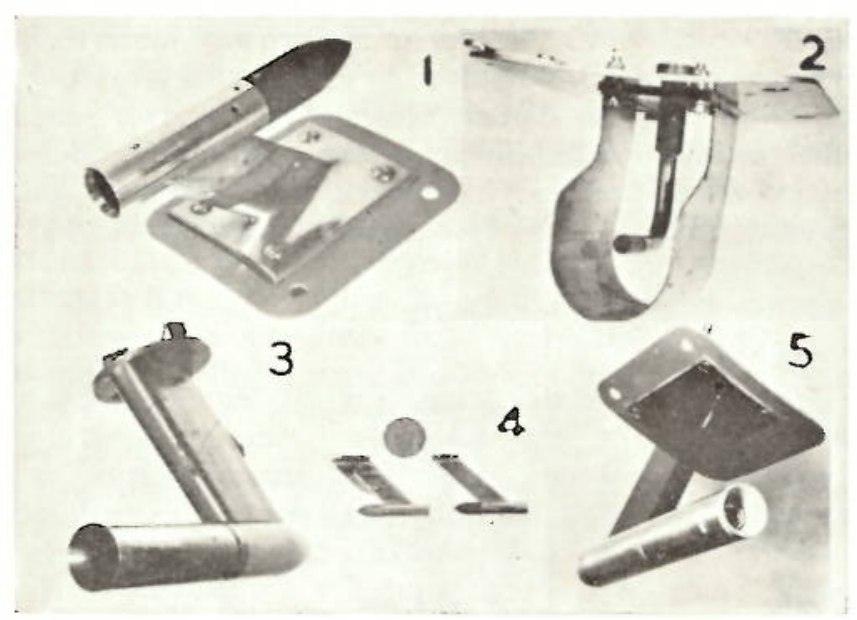

Figure 32. High temperature probes. is renewed interest in the Sherpa with the advent of hypersonic aircraft, not because of the isoclinic wing but because of the similarity in all moving tip controllers.

\section{Library \\ DOCUMENTATION RESEARCH}

For the past eighteen months, with the support of a grant from the United States National Science Foundation, an investigation has been proceeding into the comparative efficiency of various methods of indexing scientific and technical information ${ }^{(79)}$. The first stage of the programme will be completed in March 1960, when 18,000 documents will have been indexed by four different systems. The immediate objective of the project will have been attained about a year later when an intensive test programme will have been completed. It is now clear, however, that the data will be most valuable, after detailed analysis, for investigating the basic principles of indexing systems, and will assist in the design of systems which can be used for information retrieval by high speed computers.

\section{Conclusion}

The foregoing review has given an account of research either completed or in progress in nine divisions of the College of Aeronautics.

The College is not primarily a research institute. Apart from the work of Research Fellows and Assistants, the research is carried out by members of staff who have major responsibilities in teaching and by students, as a feature of their Course work. The suggestion is made from time to time that Cranfield might have a Research Division operating under the general direction of the College but somewhat detached in respect of organisation, so that the association between the two would be similar to that between, for example, Cornell University and Cornell Aeronautical Laboratory in the United States. The Cornell system necessarily involves engagement by the Aeronautical Laboratory in research as a large scale financial undertaking, with heavy reliance on commercial and state sponsors, the connection with academic instruction in the University becoming correspondingly tenuous. This arrangement is evidently acceptable in America and variations of it are in operation in most American universities and institutes of technology. In this country, the outlook of the educational establishments is different and it is believed that teaching derives the greatest benefit from research when the association between the two is most intimate. The relationship at Cranfield follows the characteristic British scheme and it is thought that it is best suited to present needs in this country.

Because of the part which research plays as a deliberate and essential component of the course of instruction, students, as has been described, have been engaged, to a greater or lesser extent, in most of the topics to which reference has been made. The theses, identified by the prefix " $T$ " in the list of references, are illustrative of the contributions made by students to a large number of research projects. As with the first 
year's post-graduate research in a university, the work in the Diploma course at Cranfield serves the double purpose of introducing men to the aims and methods of research and assisting the progress of continuing investigations.

The two circumstances, that the staff are not preoccupied with teaching an undergraduate body and that the majority of the students have had a useful amount of practical engineering experience, greatly ease for the academic staff the task of organising and supervising the student's "thesis work" and pursuing their own advanced research. It is hoped that the range and quality of the research described in this paper will be considered to justify the general philosophy underlying its conduct.

The putative authorship of this paper presents a minor problem. As was mentioned earlier, the body of the text and the illustrations were contributed by the Departments named, the Heads of Departments responsible being:

Aerodynamics: Professor J. A. J. Bennett, D.Sc., Ph.D., F.R.Ae.S.

Aircraft Design: Professor W. S. Hemp, M.A., F.R.Ae.S.

Aircraft Economics and Production: Professor J. Loxham, C.G.I.A., M.I.Mech.E., M.I.Prod.E., M.B.I.M.

Aircraft Electrical Engineering: Professor G. A. Whitfield, B.Sc., F.R.Ae.S., F.Inst.P., M.I.E.E.

Aircraft Materials: Professor A. J. Kennedy, Ph.D., A.M.I.E.E., F.Inst.P., F.I.M.

Aircraft Propulsion: Professor A. G. Smith, A.R.C.S., B.Sc., D.I.C.

Flight: Wing Commander C. G. B. McClure, A.F.C., M.A., A.F.R.Ae.S.

Mathematics: Professor G. N. Ward, M.A.

Library: C. W. Cleverdon.

\section{REFERENCES}

Published Papers

Department of Aerodynamics

1. Westley, R. and Lilley, G. M. (1952). An Investigation of the Noise Field from a Small Jet and Methods for its Reduction. C. o. A. Report 53, 1952.

2. Lilley, G. M., Westley, R., Yates, A. H. and Busing, J. R. (1953). On Some Aspects of Noise Propagation from Supersonic Aircraft. C. o. A. Report 71, 1953.

3. Green, D. J. and Lilley, G. M. (1955). Preliminary Report on the Use of the Wide Angle Diffuser in Ground Mufflers of the Type Used for Silencing Jet Aircraft. C. o. A. Note 27,1955 .

4. Lilley, G. M. (1958). On the Noise from Air Jets. (To be published in the R. \& M. series.)

5. Hodgson, T. H. and Lilley, G. M. (1959). A Brief Review of U.S. and Canadian Work on Pressure Fluctuations in Turbulent Boundary Layers. (Unpublished.) 1959.

6. Busing, J. R., Marson, G. B. and Lilley, G. M. (1955). Experimental Investigation of the Interference of a Body on a Low Aspect Ratio Wing of Rectangular Planform at a Mach number of 2. C. o. A. Note 31, 1955.

7. Busing, J. R. and Lilley, G. M. (1955). A Preliminary Investigation of the Flow over a Particular Wing-Body Combination at $M=2$. C. o. A. Note $24,1955$.

8. Marson, G. B. (1954). The Calculation of the Wave Drag of a Family of Low-Drag Axisymmetric Nose Shapes of Fineness Ratio $4 \cdot 5$ at Zero Incidence at Supersonic Speeds. C. o. A. Note 10, 1954.
9. Radhakrishnan, G. (1958). The Exact Flow Behind a Yawed Conical Shock. C. o. A. Report 116, 1958.

10. MARSON, G. B. (1956). Aerodynamic Characteristics of Two Low Aspect Ratio Rectangular Wings at $M=2$. C. o. A. Note $44,1956$.

11. Marson, G. B. and Lilley, G. M. (1956). The Displacement Effect of Pitot Tubes in Narrow Wakes at Subsonic and Supersonic Speeds. C. o. A. Report 107, 1956.

12. PoZnIAK, O. M. (1957). Investigation into the Use of Freon 12 as a Working Medium in a High-Speed Wind Tunnel. C. o. A. Note $72,1957$.

13. BARNA, P. S. (1957). Aerodynamic Characteristics of a $40^{\circ}$ Swept-Back Wing of Aspect Ratio 4.5. C. o. A. Note 65, 1957.

14. Marsden, D. J., Simpson, R. W. and Rainbird, W. J. (1958). An Investigation into the Flow over Delta Wings at Low Speeds with Leading Edge Separation. C. o. A. Report 114, 1958.

15. HaRris, K. D. (1958). Subsonic Drag and Pitching Moment Characteristics of Slender Cambered Bodies. C. o. A. Report 118, 1958.

16. Craven, A. H. (1956) A Potential Flow Model for the Flow about a Nacelle with Jet. C. o. A. Report 101, 1956.

17. Craven, A. H. (1956). The Free Streamline Method Applied to the Flow at the rear of a Duct. C. o. A. Report 99, 1956.

18. Craven, A. H. (1957). The Effect of a Jet Deflection on the Interference of a Rearward Facing Jet. C. o. A. Note $70,1957$.

19. Craven, A. H. (1957). Interference of a Rearward Facing Jet on the Flow over Three Representative Afterbody Shapes. C. o. A. Note 60, 1957.

20. Craven, A. H. (1958). Effect of Body Incidence on Two Afterbodies with Rearward Facing Jet. C. o. A. Note 92, 1958.

21. Craven, A. H. (1959). The Effect of Density on Jet Flow at Subsonic Speeds. C. o. A. Report 120, 1959.

22. Craven, A. H. (1960). Base Pressure at Subsonic Speeds in the Presence of a Supersonic Jet. C. o. A. Report 129, 1960.

23. Willmer, M. A. P. (1956). On the Generalised Simple System for Automatic Stabilisation of a Helicopter in Hovering Flight. Journal of the Helicopter Association, October 1956.

24. BRYCE, W. W. (1956). Independence of Helicopter Rotor Derivatives under Non-Uniformity of Induced Velocity Distribution at Low Forward Speed. C. o. A. Report 110, 1956.

25. OPATOWSKI, T. (1958). The Stability of Flying Platform Helicopters. Journal of the Helicopter Association, October 1958.

26. Lilley, G. M. (1952). An Investigation of the FlexureTorsion Flutter Characteristics of Aerofoils in Cascade. C. o. A. Report 60, 1952.

27. Craven, A. H. and Davidson, I. (1955). The FlexureTorsion Flutter of Cambered Aerofoils in Cascade. C. o. A. Report 95, 1955.

28. MiLne, R. A. and Willox, F. G. (1955). Measurements of the Derivative $z_{w}$ for Oscillating Wings in Cascade. C. o. A. Report, 1955.

29. Craven, A. H. (1960). Aerodynamic Derivatives of an Aerofoil Oscillating in an Infinite Staggered Cascade. C. o. A. Report 125, 1960.

30. Spillman, J. J. (1959). Some Thoughts on Slender All Wing Supersonic Air Liners. C. o. A. Note 87, 1959.

31. Nonweiler, T. R. F. (1958). The Man-Powered AircraftA Design Study. Journal of the Royal Aeronautical Society, October 1958.

32. BiRD, G. A. and Lilley, G. M. (1957). On the Choice of the Working Fluid for Intermittent Supersonic Wind Tunnels. C. o. A. Report 112, 1957.

33. Cllarke, J. F. (1958). Energy Transfer Through a Dissociated Diatomic Gas in Couette Flow. Journal of Fluid Mechanics, September 1958.

34. Lilley, G. M. (1959). A Simplified Theory of Skin Friction and Heat Transfer for a Compressible Laminar Boundary Layer. C. o. A. Note $93,1959$. 
35. Clarke, J. F. (1958). Chemically Reacting Gas Flows. C. o. A. Report 117, 1958.

36. Clarke, J. F. (1958). The Linearised Flow of a Dissociating Gas. (Unpublished.) 1958.

37. Cleaver, J. W. (1959). Characteristics Theory Solutions of a Two-Dimensional Ideal Dissociating Gas Flow. C. o. A. Report 123, 1959.

38. Clarke, J. F. (1960). On the Sudden Contact Between a Hot Gas and a Cold Solid. C. o. A. Report 124, 1960.

Department of Aircraft Design

39. LINGE, E. R. (1956). Investigation into a Photoelastic Method for the Direct Measurement of Surface Strains in Metal Components. C. o. A. Report 97, 1956.

40. Hemp, W. S. (1955). On the Application of Oblique Co-ordinates to Problems of Plane Elasticity and SweptBack Wing Structures. Aeronautical Research Council R. \& M. 2754, 1955.

41. Hemp, W. S. (1955). Stress Analysis of Multi-Web Boxes. Fifth Anglo-American Aeronautical Conference, June 1955. Published by Royal Aeronautical Society.

42. Griffin, K. H. (1956). Certain Methods of Stress-Analysis of Particular Multi-Web Box Beams. C. o. A. Report 108, 1956.

43. Howe, D. (1956). An Approximate Solution to the Swept Wing Root Constraint Problem. C. o. A. Report 98, 1956.

44. Houghton, D. S. (1958). The Influence of Frame Pitch and Stiffness on the Stress Distribution in Pressurised Cylinders. C. o. A. Note 79, 1958.

45. Houghton, D. S. and Chan, A. S. L. Aircraft Pressure Cabin Analysis, An Extension of Existing Theory. (To be published in Aircraft Engineering.)

46. Houghton, D. S. and Chan, A. S. L. (1958). Discontinuity Stresses at the Junction of a Pressurised Spherical Shell and a Cylinder. C. o. A. Note 80, 1958.

47. Lempriere, B. M. (1958). Thermal Stresses in a Box Structure. C. o. A. Note 84, 1958.

48. JoHns, D. J. (1958). Thermal Stresses in Thin Cylindrical Shells Stiffened by Plane Bulkheads for Arbitrary Temperature Distributions. C. o. A. Note 83, 1958.

49. Hemp, W. S. (1956). Fundamental Principles and Theorems of Thermo-Elasticity. The Aeronautical Quarterly, Vol. VII, August, 1956

50. Emslie, B. (1959). Some Values of the Reduction Factor for Plastic Buckling of Plates in Shear. C. o. A. Note 90, 1959.

51. Preston, C. (1954). Some Bearing Materials under High Pressures at Low Rotational Speeds. C. o. A. Note 12, 1954.

52. Hemp, W. S. (1958). Theory of Structural Design. C. o. A. Report 115, 1958.

53. Houghton, D. S. and Chan, A. S. L. (1957). The Design of a Multi-Cell Box in Pure Bending for Minimum Weight. C. o. A. Note 74, 1957.

54. Johns, D. J. (1958). Optimum Design of a Multi-Cell Box Subjected to a Given Bending Moment and Temperature Distribution. C. o. A. Note 82, 1958.

55. Houghton, D. S. and Chan, A. S. L. The Design of a Pressurised Missile Body under Axial Compression. (To be published in Aircraft Engineering.)

56. Johns, D. J. (1958). Some Panel Flutter Studies using Piston Theory. Journal of the Aeronautical Sciences, November 1958.

57. JoHns, D. J. The Influence of Panel Deformations on Wing Flutter. (To be published in the Journal of Aerol Space Sciences.)

58. JoHNS, D. J. and PARKS, P. C. Influence of Structural Damping on Panel Flutter. (To be published in Aircraft Engineering.)

59. Howe, D. (1959). Use of Models in Helicopter Vibration Analysis. The Aeroplane, pp. 16-18, January 1959.

Department of Aircraft Propulsion

60. Goodger, E. M. (1957). Spontaneous-Ignition Data of Hydrocarbons and Aviation Fluids. C. o. A. Note 68, 1957.
61. Sмrth, A. G. A Theory of Resonance of Solid Rockets Based on Constant Propellant Surface Temperatures. (To be published.)

62. Carton, D. S. (1959). Minimum Propulsion for the Soft Moon Landing of Instruments. C. o. A. Note 94, 1959.

63. Goodger, E. M. (1958). The Ignition of Gaseous Mixtures by Heated Surfaces. London University Ph.D. Thesis. Internal, 1958.

64. GoOdGer, E. M. (1956). The Influence of Engine Speed Upon Pre-Ignition. C. o. A. Note 51, 1956.

65. GoOdger, E. M. (1955). The Combustion Characteristics of a Cylindrical Rod Burner System. C. o. A. Report 90, 1955.

Department of Economics and Production

66. Harris, J. T. (1960). Clearance Fits and the Limits on Mating Parts. C. o. A. Note 96, 1960.

Department of Aircraft Electrical Engineering

67. Paul, R. J. A. and MaXwell, M. E. (1958). The General Trend Towards Digital Analogue Techniques. Proceedings of International Analogue Computation Meeting, Strasbourg, pp. 403-406, 1958

68. Brown, D. C. and FARADAY, B. P. (1957). A Transistorised Radiation Monitor. C. o. A. Note 66, 1957.

69. Brown, D. C. and Henderson, F. (1957). The $p-n$ Junction as a Variable Reactance Device for f.m. Production. C. o. A. Note 76, 1957.

70. Brown, D. C. (1958), A Variable Delay Line. C. o. A Note $81,1958$.

71. Adams, K. M. (1956). On the Synthesis of Three-Terminal RC Networks. C. o. A. Report 96, 1956.

72. Deards, S. R. (1956). Notes on the Theory of Planar Electric Networks. C. o. A. Note 52, 1956.

Department of Aircraft Materials

73. HinchClifFe, S. and Jones, J. W. (1955). An Investigation into the Effect of Subsonic Vibrations during the Period of Solidification of Castings with Particular Reference to a Material for Gas Turbine Blades. C. o. A. Report 89, 1955

74. JoNES, J. W. and JAGACIAK, J. (1955). Effect of Vibration Sonic and Subsonic Frequencies during the Period of Solidification, on the Mechanical Properties of H.R. Crown Max and Nimonic C75. C. o. A. Report 91, 1955.

Department of Mathematics

75. WARD, G. N. (1955). The Drag of Source Distribution in Linearized Supersonic Flow. C. o. A. Report 88, 1955.

Department of Flight

76. Burrows, F. M. (1956). A Theoretical and Experimental Study of the Boundary Layer Flow on a $45^{\circ}$ Swept-Back Wing. C. o. A. Report 109, 1956.

77. Burrows, F. M. (1956). A Note of Some Equipment used for Boundary Layer Measurements in Flight. C. o. A. Note 49, 1956.

78. GEORGE, J. M. The Measurement of Air Temperature in High Speed Flight. (To be published.)

Library

79. Cleverdon, C. W. (1958). The Evaluation of Systems used in Information Retrieval. International Conference on Scientific Information, Washington, 1958.

Unpublished Theses

Department of Aerodynamics

T1. Peduzzi, A. Nature and Suppression of Noise from a 1 in. Diameter Circular Jet. (1952).

T2. Woods, B. A. The Supersonic Flow Around a Yawed Cone. (1956).

T3. Radhakrishnan, G. and CoOte, M. A. Measurements of the Pressure Distribution over Low Drag Bodies of Revolution at Incidence in Supersonic Flow. (1957).

T4. Grimson, J. Flow Separation on Cones at Incidence in Low Speed Flow. (1958). 
T5. Clancy, L. J. and Smirh, P. M. Flow Over a Delta Wing with Leading Edge Separation. (1958).

Drummond, A. M. and Richardson, J. Flow Over a Delta Wing with Leading Edge Separation. (1959).

T6. Brown-Edwards, E. G. and Wesson, N. J. The Characteristics and Flow over a Yawed Slender Delta Wing Having $10 \%$ Thickness with Twin Fins. (1959).

T7. SusseX, A. D. and Felton, P. R. Investigation of High Lift Devices and Controls on Slender Wings. (1958).

T8. Gallagher, T. and Williams, R. Mixing of Inclined Jets with a Uniform Flow. (1959).

T9. Ayers, R, F and WILDE, M. R. Aerodynamic Characteristics of a Swept Wing with Spanwise Blowing. (1956).

T10. KisielowSKI, E. Potential Flow Past a Circular Cylinder with a Simulated Jet. (1957).

Hersee, E. H. W. and Hipp, A. Potential Flow Past a Circular Cylinder with a Simulated Jet. (1956).

T11. SHEIKH, M. A. An Investigation of the Flexure-Torsion Flutter Characteristics of Aerofoils in Cascade. (1953).

T12. Cleaver, J, W and Thomson, F. The Melting Characteristics of Bodies in a Heated Airstream at Supersonic Speeds. (1959).

T13. HARRIS, T. M. Interaction of a Flow of Ionized Argon Behind a Strong Shock Wave with a Steady Magnetic Field. (1959).

\section{Department of Aircraft Design}

T14. Halliwell, A. R. Stress Distribution in a Delta Wing. (1956).

T15. Sharman, P. E. W. Stress Analysis of Swept Cantilever Plates. (1956).

T16. Chopra, P. D. Investigation of the Stress Distribution in a Multi-Spar Swept Box. (1955).

T17. Coull, A. Theoretical Investigation of the Stress Distribution in Swept Cantilever Plates. (1955).

T18. ARthurs, T. D. On the Stress Concentration Around Pressure Cabin Cut-Outs under other than Pressure Loading. (1959).

T19. Rothwell, A. On the Stress Concentration Around Unreinforced Square Cut-Outs with Rounded Corners in a Pressure Cylinder. (1958).

T20. Hillel, A. Reinforced Circular Cylinder under Internal Pressure. Stress Distribution around a Cut-Out. (1956)

r21. Ashmead, F. A. H. The Thermal Conductivity of Joints with a View to Temperature Prediction in Built-Up Structures. (1955).

T22. LovatT, J. D. Temperature Distribution in Structures Resulting from Aerodynamic Heating. (1956).

T23. Nichors, R. The Stability of "Honeycomb" Sandwich Panels in Shear. (1955)

T24. NAYLOR, H. F. The Effect of Curvature on Initial Buckling and Failure of Stiffened Curved Panels in Compression. (1953).

T25. SMITH, D. H. Investigation into the Plastic Buckling of Plates in Shear. (1957).

T26. Kirton, J. L. Creep Phenomena in Structures. (1959).

T27. Swanson, S. R. Fatigue Assessment of Aircraft Structures. (1958).

T28. PePper, D. H. Observations on the Mechanism of Fast Fracture in Ductile Materials. (1957).

T29. Etchells, R. Crack Propagation in Fatigue and its Relation to Pressure Cabin Design. (1959).

T30. Rowland, K. A. Design and Resonance Testing of Dynamic Model of a Swept Winged Aircraft and Comparison with Full Scale Tests. (1950).

T31. PenNell, W. E. Investigation into the Loads Developed on Outrigger Undercarriage Units. (1958).

T32. SMrTh, B. Further Development and Use of a Vector Method of Analysis in the Separation of the Normal Modes of Vibration of a Complex Structure. (1958).

T33. Sevier, H. G. An Experimental Investigation of Helicopter Ground Resonance. (1952).

T34. COOKE. A. An Investigation of the Theory of SelfExcited Mechanical Oscillations of a Helicopter. (1953).

T35. SMITH, E. H. Model Helicopter Ground Resonance Testing. (1955).
T36. REED, P. R. Ground Resonance Testing of the Skeeter Helicopter Dynamic Model. (1957).

T37. Topp, K. F. The Torsional Vibration of a Helicopter Transmission System-An Investigation of Mechanical Analogue Techniques. (1958).

Department of Aircraft Propulsion

T38. Seyb, N. J. The Whirling of a Rotor System Mounted in Flexible Bearings. (1959).

T39. BAKER, A. G. J. An Investigation into the Ground Effects of Convergent-Divergent Nozzles. (1959).

T40. Green, T. The Interaction of Jets with Surfaces. (1958).

T41. Dawson, W. F. An Investigation into the Possibility of Ignition Through Shock Waves, and the Principles Considered in a Ram-Jet. (1958).

T42. LeONARD, I. C. A. Shock Ignition and its Application to Ram-Jets. (1959).

T43. Glanister, C. F. M. Flame Stability in a Cascade of Porous Blade Burners. (1959).

T44. Little, J. P. Combustion of Special Fuels-Hydrogen as an Aviation Fuel. (1958).

T45. Lucas, G. G. Hydrogen as an Aviation Fuel (1958).

T46. Callaghan, W. M. Combustion of Slurry Fuels. (1958).

T47. HeNSHAw, J. B. Research into Slurry Fuels. (1959).

Department of Economics and Production

T48. CreE, A. H. An Investigation into the Standards of Accuracy Attainable on High Precision Grinding Machines Operating under Carefully Controlled Conditions of the Type which could be Reproduced on a Commercial Basis. (1959).

T49. Norbury, C. J. The Application of Memo-Motion to Industrial Operation. (1954).

T50. AYre, K. H. An Investigation into the Applications of Non-Continuous Memo-Motion in Industry. (1958).

T51. BowLES, I. E. J. The Development of Photo-Sampling Techniques in Work Study. (1959).

Department of Electrical Engineering

T52. PENNY, M. F. A Grid Controlled Photo-Multiplier. (1959).

T53. LEE, K. C. A Parallel Binary Adder using Surface Burner Transistors. (1959).

T54. FreEn, D. A Radioactive Method for the Measurement of Small Displacement. (1959).

T55. Baughen, J. E. A Pulse-Width Modulated/Frequency Modulated Subcarrier Generator using the Hole Storage and Variable Reactance Properties of a Transistor. (1959).

T56. MOTEN, J. M. The Human Operator in a Closed Loop System. (1959).

T57. Sheppey, G. C. Two Approximation Procedures for Network Synthesis. (1958).

T58. LEAT, A. F. V. Sketch for a General Theory of Equivalent $n$-ports. (1957).

T59. AвRAham, D. Synthesis of Electric Networks for Specified Response in the Time Domain. (1955).

T60. Hodgson, T, H. Combinatorial Topology and Electrical Network. (1956).

T61. Mitchell, H. D. Development of a Digital ProductIntegrator for the Evaluation of Convolution Integrals. (1955).

T62 Mercer, D. Methods of Binary-Decimal Data Conversion Using Saturable Reactors. (1955).

T63. Venkateswaran, G. Analysis and Design of a Transistor Analogue-Digital Converter. (1958).

T64. Thomas, N. V. Design Techniques for Servomechanisms. (1959).

T65. FlegG, H. G. The Manipulation and Minimization of Boolean Switching Functions. (1959).

T66. ToplIS, J. E. Transistorized Transient Recorder. (1957)

T67. Dent, C. W. Accurate Distance Measurement using a Magneto-Strictive Delay Line. (1959).

T68. SoDHI, J. S. Generalisation of the Strecker-Feldtkeller Matrix Theory of Linear Quadripoles. (1956).

T69. Davison, R. C. Radio Frequency Currents in the Metal Surface Around a Notch Aerial. (1956). 
T70. Gray, R. I. The Measurement of Surface Current and Charge at Centimetric Wavelengths in the Determination of Radar Echoing Areas. (1957).

T71. BYERS, D. J. A Survey of Surface Current Measuring Systems and a Technique for the Assessment of their Accuracy. (1958).

T72. Kshirsagar, A. R. A Method to Determine Direct Axis Transient Reactance and Direct Axis Short Circuit Time Constant of Aircraft Alternator. (1959).

T73. McKay, J. P. Transient Resistance of d-c Generators. (1956).
T74. SINGH, H. Investigation into the Effects of Rectifier Loads on a Three-Phase Alternator. (1958)

T75. Stopher, H. E. On the Nature of the Hysteresis Motor. (1959).

Department of Mathematics

T76. ClanCy, L. J. An Investigation into Some Errors Involved in a Numerical Process for Evaluating the Wave Drag on Non-Lifting Slender Bodies in Linearised Theory. (1958).

\section{DISCUSSION}

Professor Mair: He would like to take this opportunity of reinforcing what Professor Murphy had said about the good relations between Cambridge and Cranfield; the planners of Cranfield thought very carefully about this when they decided to place it the same distance from Cambridge as from Oxford. With a fine sense of balance they made it just a little bit farther away from London.

He would also like to reinforce what Professor Murphy had said about research and particularly to agree with him about not having a research division on the lines of Cornell Aeronautical Laboratory. It might be a great pity if Cranfield started yet another division-which might be half way between Cranfield and Cambridge, but separated from everywhere. It was a most important feature of Cranfield that the research was so closely mixed up with the teaching.

The striking thing about Cranfield and about Professor Murphy's accounts of it, was the enormous range covered, from man powered aeroplanes to flight at ten or twenty times the speed of sound. This wide range left those present that evening free to ask questions about almost anything in engineering, especially since Professor Murphy had brought with him an impressive range of experts.

A Speaker: The only pictures that they saw of supersonic air liners had no windows. Was it now accepted that the supersonic air liners of the future were to have no windows?

Mr. Masefield: He could only say that in the supersonic transport investigations on which they were engaged at the moment there were windows. They were made of quartz, because of the heating problem, and some of these were being investigated in the Bristol 188 research highsupersonic aeroplane which, as they knew, would be flying before long; his own feeling was that passengers hated being shut up in "black boxes" and they must be allowed to have some orientation by giving them some windows. It was often said that there was nothing to see, but that was rubbish; at 60 or $70,000 \mathrm{ft}$. one could get some wonderful views of continents far below, clouds and the rest of it. It was well worth while looking out. The penalty in weight was not one that they had to worry about too much. It was heavier, of course, but not so heavy that they could not cope with it, and to give an attractive cabin was well worth while. The shape of the aeroplane, which varied just a little from the one illustrated, the one that his company was working on at the moment, did permit windows to be offered in the conventional sort of places.

A Speaker: To what extent was the use of spot welding on aircraft being investigated for stainless steel wings?

A. F. Newell (College of Aeronautics, Assoc. Fellow); The aircraft referred to by the questioner was projected as a Design Exercise in 1953. The wing was of multi-cell stainless steel construction and was puddle-welded. They had co-operated with the British Oxygen Company on the development and feasibility of doing such welding and produced a number of sample specimens. The "real" experience on this type of welding, however, was with Bristol's The Bristol 188 was a "Secret" aeroplane, but if the chairman would like to comment on their practice the question could be answered. The point of interest from the point of view of the College was that theirs, a similar aeroplane, was being projected at the same time as Bristol, and their satisfaction had been to find since that they were thinking of identical methods of construction.

Mr. Masefield: The 188 was extensively puddle-welded and in fact had little riveting at all. Stainless steel welding had been one of the great problems in building this aircraft, in fabricating the structure almost entirely from welded stainless steel and getting double curvatures onto some of the forms in the very thick plates that had been used to overcome the heating and the "thermal thicket" problems that were going to be encountered. It seemed to be working out pretty well, in fact, and the surface finish had come out remarkably smooth: it could then be polished down to give an effect rather better than the best flush riveting could achieve. He thought that for more than a Mach 2.4 aeroplane they would have to have welded steel structures.

A Speaker: Was every weld inspected or was some sort of sample taken?

Mr. Masefield: Every weld had to be inspected.

Professor Murphy: The questioner had put his finger on one of the most interesting problems in metallurgy because any welded component, particularly where the metal had been taken to the fusion point, presented a most complex metallurgical condition. It was one of those things which had worked and therefore one used it and now one was investigating it to find out why it worked so well. Had it been the other way round, and metallurgists had been asked to predict what such a mixed structure would do in practice, they would have hesitated to speak as confidently as they could now with the benefit of practice behind them. There was a great deal of work to be done still with each different material in assessing what the possible variation was, not only in the soundness of the weld, but in the metallurgical constitution as well.

E. J. Catchpole (C.I.B.A. (A.R.L.) Ltd., Associate Fellow): He was interested to note, in reading the newspaper that morning that not all the research undertaken by Cranfield students was carried out there. One of the students had recently been awarded a $£ 400$ scholarship and had decided to spend it on a 35,000 mile tour round 
the world to see what aviation conditions were like in remote areas.

Where did the bulk of the money come from for buying and operating the equipment that Cranfield had? It seemed to him that this was an important matter; for example, he had personal experience in the U.S.A. of a typical Institute of Technology which received about 85 per cent of its research money-about $£ 1,000,000$ per yeardirect from industry or from the Government. He could see Professor Murphy's point that it was a good thing not to tie research too closely to industry, but if one did not do that, where did one get the money from? Was it, so far as this country was concerned, economical to have expensive equipment of this type without making it work directly for industry?

Another point which interested him was the position of this very excellent and special College of Aeronautics. How, again, did this relate to an Institute of Technology in which there were many other technologies represented? They talked these days in the Aircraft Industry of "diversification "; in other words, the application of their special knowledge to non-aircraft fields. On the other hand, more and more fields were taking on greater importance for aircraft applications. For example, fields such as ceramics (in which missile people were interested), chemistry (for many purposes) and atomic energy. How did the College of Aeronautics relate itself to those subjects, and should it perhaps be more diverse?

In the U.S.A. there was a considerable interchange of staff with industry. It was regarded as normal for a Professor to spend perhaps a year in industry in the middle of his academic teaching, and this seemed to be an excellent thing. What were Professor Murphy's views on this in relation to the Cranfield staff?

$\mathrm{He}$ was interested to hear that there was a good deal of work going on at Cranfield on optimum structures. That was a most important field on which a great deal remained to be done inasmuch as it lead to structural synthesis-how to build up a structure so as to best carry the known loads-a very time-saving operation. He felt that it would be a good thing if at some time the main Society could have a lecture on what was being done by Professor Hemp and his associates.

$\mathrm{He}$ felt that the research done at the College of Aeronautics (as in other institutions) was not all getting across to the Industry, although it was, of course, published in the College reports. Had Professor Murphy any suggestions as to how best to get the aircraft designers to appreciate the value of this work?

Professor Murphy: The College and its activities were financed in the main by the Government through the Ministry of Education. This applied to most of the research, but where research was sponsored by a Government Department or by a firm, then there was with that sponsoring a financial contribution which either paid for the whole of the research or made a valuable contribution to it. Whether a thing was an economic proposition depended on whether one thought one was getting value for one's money. Following on from this was the question of whether it was a good thing to refrain from soliciting more sponsored research from industry. On the whole they thought that the balance they had was not bad. $\mathrm{He}$ would say that there was no research going on at Cranfield which could not be seen to have a real educational content and this test they tried to apply to any research proposition that was put to them.

$\mathrm{He}$ believed that the Ministry of Education pursued in these matters a far-sighted and wise policy. The College had to account very carefully and strictly for how they spent the money, but he did not think they had any reason for saying that they were seriously inhibited from any justifiable activity in research or education that fell reasonably within the terms of their foundation. He should also say, of course, that they greatly appreciated the help they got from the Aircraft Industry.

There was a reference to diversification, and it was true that the boundary between what could be called aeronautical and other forms of engineering or applied science became rather shaded. Their policy was that they could see no reason against following that tendency and, in fact, this had had a natural effect in that they found themselves now offering diversified courses, mostly of a year's duration, outside their Diploma Course. They recognised that a good deal of their teaching was related to other branches of applied science or engineering than those which might be considered as limited to aeronautics.

Exchange with industry of staff-this was very easy to say and very difficult to apply in this country. In America and in most European countries there was a much greater flexibility and facility of exchange of technical people between industry and academic institutions. The tradition in England had never gone that way. $\mathrm{He}$ thought the College did pretty well, however, in achieving a similar result in a different way. They had very close contacts with industry, not only by visits from people in industry to the College and vice versa, but by the service of College academic staff on, for instance, Government Committees, alongside men from industry, and he personally felt satisfied that they missed little in this contact between members of the staff and industry. The point made on publication was very interesting indeed and in the full text of the lecture he had dealt with this to some extent. The College of Aeronautics Reports and Notes achieved good circulation among strictly aeronautical people. He believed, however, that as the process of diversification went on this would become less and less a completely satisfactory means of disseminating information about the research at Cranfield. Without in any way departing from the practice of offering their aeronautical papers to the Royal Aeronautical Society, they were going to have a look into the submission of papers to some of the other learned bodies-engineering, metallurgical, perhaps ceramic, societies.

A Speaker: Was this the first time that the British Industry had adopted the engines in and around the tail section?-and, if so, what advantage were they, other than passenger comfort?

Mr. Masefield: He could not, of course, go bail for Cranfield's designs, but there was an increasing tendency to concentrate engines in the rear of the aeroplane. The French had a great deal to be proud of in that they led the way with the Caravelle, although the Caravelle was not necessarily the very first aeroplane on which this was applied, but it was the first really successful aeroplane, and, as they knew, in the Vickers VC-10 and the VC-11 and in the DH121, in the Bristol 205 and one or two other aeroplanes, the new fashion of putting the engines at the back end had been adopted. It was a pretty good idea from a number of points of view, particularly in getting the wing really clean, for fairly high subsonic speeds; getting the engines off the wing was a very good thing indeed, apart from the fact that they were rather useful to relieve bending loads in certain aeroplanes. $\mathrm{He}$ thought they 
would see this idea of putting engines in the rear growing more and more and there was no doubt that aerodynamically it worked well, although it had quite a lot of problems from a centre-of-gravity balance point of view, particularly as engines often grew heavier as they grew in power and therefore one had to put more length on the nose of the aeroplane to balance the fact that there were bigger and better engines. So the general tendency of the aeroplane was to grow longer and longer in front as it got more and more power at the back, and this, perhaps, was a good thing because the more capacity one put in the cabin of a civil aeroplane, the more it was able to earn money.

Professor Murphy: Was it a serious consideration that for passenger aircraft the noise was more reduced?

Mr. Masefield: It helped although there was some compressor noise in the back of the cabin.

Professor Hemp (College of Aeronautics, Fellow): Was it not true that as the engines got so much more powerful they made so much noise that they might shake the structure to pieces?

Mr. Masefield: Getting the noise away from the structure was certainly a good thing.

N. K. Benson (C.I.B.A. (A.R.L.) Ltd., Graduate) : Could Professor Murphy say what Cranfield's attitude was to space research?

Professor Murphy: The Minister for Science had said something on this subject. They had no vaunting ambitions to send a man very far up into space. They did think, however, that it would not be unreasonable, were there a demand, for the College to offer a course in space technology. It was, after all, the gathering together of various branches of aeronautical science plus more physics and so on, and they were turning over in their minds what support there would be for, say, a twelvemonth's course of instruction in space technology.

A Speaker: Could Professor Murphy say if Cranfield were interested yet, or would be interested, in the serviceability of all those parts which went to make up a complete aircraft?

Mr. Masefield: He would say from the Chair that he hoped that Cranfield would be interested in this.

Professor Murphy: Was this in relation to research directed to that end?

A Speaker: Research directed towards the reliability of engines, airframe instruments and all the components on which the safety and usefulness of an aircraft depended.

Professer Murphy: He would say that as soon as the question of maintenance became amenable to a scientifically philosophical approach, then it was the affair of Cranfield and, since it was something close to his heart, he would ask Professor Whitfield to reply.

Professor Whitfield (College of Aeronautics): $\mathrm{He}$ thought that this was mainly a financial problem. Perhaps the worst reputation for any reliability in aircraft was that of electrical and electronic equipment. That was exactly what one would expect. Electrical equipment for aircraft was not developed.
A prototype was designed and a very small number, sometimes only one or two, were made. These were operated under unrealistically good conditions and the more obvious faults corrected. The one or two final models were run, still under unrealistically good conditions, for perhaps one thousand hours. Production models were then supplied to the aircraft firm and installed in aeroplanes. The real requirement was for reliable operation for the order of 10,000 hours, with periodic maintenance. It was not surprising that failings occurred very much more frequently. Eventually, after some years of airline operation, the reliability was raised to a reasonable level.

If equipment designers were given the facilities for a reasonable amount of ground running, under fairly severe conditions, of a number of production models, most of the design faults would be removed before use in flight. This would be expensive but not as expensive as the present practice in which aircraft were used as test beds for equipment development.

Mr. Masefield: Ninety-five per cent of civil aircraft unreliability was either electrics or hydraulics, and most of that was from components which, as Professor Whitfield had said, had not really been designed for the job. Fortunately, as the result of fifteen years of beating about since the war, a lot of the equipment was getting some semblance of reliability now. Viscounts, Comets and Britannias between them had established enough hours, something over a million and a half hours between them, to have got some components pretty reliable, and a number of aircraft manufacturers had said that, in any new aeroplane, they would have no new electrical or hydraulic components; they would only have those which had been proved in Viscounts, Comets and Britannias. This, he thought, could be a major advance in the next generation of British aircraft. The trouble was that, when it came to supersonics, they would have to have a new lot of electrics and hydraulics to stand the thermal thicket, and that was where they might be in trouble if they did not, as Professor Whitfield had said, get in 10,000 hours somehow before putting them into service. This was a matter for rigs on the ground-whether it was a Cranfield problem or not was a matter for debate.

A Speaker: Did researches at Cranfield indicate that man power would be used in flying machines?

Professor Murphy: Some effort at man powered flying trials went on at Cranfield, but those which got mentioned in the Press were not a research activity of the College of Aeronautics. They thought it was right to provide the necessary facilities for enthusiasts by way of hangarage and so on. On the subject of man powered flight in general, he would say that Cranfield's interest had taken a different course since the demonstration by Mr. Nonweiler that, according to his calculations, and from some experimental work, it was possible for two men, using a tandem cycle, to get themselves airborne and stay airborne for a period of time. Experimental work at Cranfield had not been taken farther than that at present.

A. J. Barrett (Head of Technical Department, Royal Aeronautical Society, Associate Fellow): Might he develop the point raised by $\mathrm{Mr}$. Catchpole concerning the philosophy of American Colleges in carrying out research in separate Institutions? He thought that they had been given an unsatisfactory reason by the Lecturer and by Professor 
Mair as to why British Institutions did not follow the same philosophy. The tradition of British Institutions in separating the teaching and research functions needed some examination if they wished to attract financial support for research activity. There was, he thought, an association between applied research and training as there was between fundamental research and education; from his experience of one American Institute they were sensitive to this subtlety in the United States. In deciding to undertake applied research, which was what generally attracted the big money, American colleges realised that the sponsors would not wait upon the conveniences of an academic schedule for the results. Accordingly they isolated their applied research activity in a separate organisation and left their main Institution to devote itself to training or to education and fundamental research. Fundamental research could not be carried out if it were subjected to a time scale set by a sponsor or, indeed, anyone else, but its requirements were not incompatible with those of established academic routine.

$\mathrm{He}$ wondered if Professor Murphy would agree that what was traditional about British Universities was that they had been concerned with education and that fundamental research, which was associated with this function, had been their main research activity in the past. On this basis, he would like to ask whether Cranfield intended to be a training body or an educational body and, if it were to be the latter, might they look forward to more fundamental work of the type which Professor Murphy had so interestingly described as that on materials and optimum structure?

Professor Murphy: He would not like to convey the impression that this question of the relationship between a teaching institution and research was beyond debate. There was a lot to be said on both sides. He refused to follow the suggestion of Mr. Barrett's at the end that either one was doing applied research or fundamental research and that that set one off onto one or the other of widely divergent courses. $\mathrm{He}$ did not believe that. $\mathrm{He}$ believed that the British system was best, not because it was a British system, but because if the job of an institution was primarily to teach then it must not get itself in the position when other considerations would direct the mental preoccupations of its staff. $\mathrm{He}$ was quite certain that in the big research institutions nominally associated with centres of learning and teaching, the people concerned with policy there became very heavily preoccupied with ensuring that next year and the year after they would have a sufficient income from sponsored research to maintain the establishment which had been built up. One saw an establishment nominally handling $30,50,100$ graduates a year, with a staff on its research institute allegedly associated with it, numbering a thousand. Now, where was the major mental concern of the people leading that whole thing going to be? Surely it would be with making a successful "business" of the research side. This compelled them-not from any unworthy motives-to follow and adopt programmes of research which were of generally relatively short-term interest to the sponsors. Some American institutions were fortunate because the Government agency sponsoring that research took a very broad view of their responsibilities-but it was not always so. In his mind this was the major objection to building up too large a research institute in close association with a centre of teaching. He did not agree that one must deal exclusively with fundamental research or exclusively with applied research; he thought that in this country they made a sensible and satisfactory blend. This, he was satisfied, after a good deal of thought, was the right way of dealing with it.

Mr. Masefield: They were grateful to Professor Murphy for his wide exposition of Cranfield's research activities; the wide field covered was impressive. The Industry was grateful for help on the abstruse problems which from time to time were pointed in Cranfield's direction.

Research was the life blood of the Industry. It had been said that life was the art of drawing sufficient conclusions from insufficient premises and the job of research was to try to get a few of those premises more sorted out. Industry was sometimes extremely confused about these things. Walking through his Company's missile shop the other day, he noticed that an article of Embodiment Loan, a warhead of a missile on which, as Professor Murphy mentioned, some research was being done, was labelled "For the purposes of storage this warhead has to be stored with the top at the bottom and the bottom at the top. To avoid confusion, it will be seen that the top is clearly labelled "Bottom" and the bottom is clearly labelled "Top." A little research on some of the aspects of that might have been an advantage!

He wished that Professor Murphy would elimate the use of that Americanism "Dutch roll" from his descriptions. It had crept in from the U.S.A. and should be eliminated.

Professor Mair: As expected this had been a great occasion, Professor Murphy had given them much to think about. They were very grateful that he had brought his colleagues to Cambridge as well and he had much pleasure in proposing the vote of thanks. 